\title{
IDENTIFICATION OF ROOT CAUSE OF VIBRATION OF A LIQUID- GALLIUM-COOLED SILICON MONOCHROMATOR AND RECOMMENDATIONS FOR ABATEMENT
}

by

\author{
S. S. Chen, S. Zhu, M. W. Wambsganss, and J. A. Jendrzejczyk \\ Energy Technology Division
}

W. K. Lee

Experimental Facilities Division

DISCLAMMER

August 1994

\begin{abstract}
This report was prepared as an account of work sponsored by an agency of the United States Government. Neither the United States Government nor any agency thereof, nor any of their employees, makes any warranty, express or implied, or assumes any legal liability or responsibility for the accuracy, completeness, or usefulness of any information, apparatus, product, or process disclosed, or represents that its use would not infringe privately owned rights. Reference herein to any specific commercial product, process, or service by trade name, trademark. manufacturer, or otherwise does not necessarily constitute or imply its endorsement, recommendation, or favoring by the United States Government or any agency thereof. The views and opinions of authors expressed herein do not necessarily state or reflect those of the United States Government or any agency thereof.
\end{abstract}

Work supported by

\section{U. S. DEPARTMENT OF ENERGY \\ Office of Basic Energy Sciences}




\section{DISCLAIMER}

Portions of this document may be illegible in electronic image products. Images are produced from the best available original document. 


\title{
IDENTIFICATION OF ROOT CAUSE OF VIBRATION OF A LIQUID- GALLIUM-COOLED SILICON MONOCHROMATOR AND RECOMMENDATIONS FOR ABATEMENT
}

by

\author{
S. S. Chen, S. Zhu, M. W. Wambsganss, J. A. Jendrzejczyk, and W. K. Lee
}

\section{Introduction}

Perfect single crystals of silicon are used to monochromate the high-intensity X-ray beams in the Advanced Photon Source at Argonne National Laboratory. Depending on the crystal geometry and the insertion device, the crystal may absorb anywhere from several hundred watts to in excess of a thousand watts. To minimize the thermal distortions in the crystal, this heat must be efficiently removed. Several approaches to this problem are being developed at the APS, including the use of inclined-crystal geometries, cryogenic cooling, liquid-gallium cooling, thin crystals, and the use of diamond. Most of these approaches require coolant flow within the crystals themselves. One issue of concern is the flowinduced vibrations. Two series of tests were performed earlier for a nearprototypical gallium-cooled crystal $[1,2]$. This LS note describes a series of tests to measure the general vibration response characteristics of a complete liquid-galliumcooled inclined-crystal monochromator system.

\section{Objectives}

The main objective of this work is to identify the root cause of vibration and to recommend general guidelines for abatement of vibration. This is achieved by performing tests to understand the response characteristics under various conditions, by analysis of the response data, and by use of some theoretical considerations. It was decided that this initial study would measure the crystal vibrations of the fully integrated monochromator system. Then, after analysis of the results, a component-by-component study would be performed in the future, as needed.

\section{Design Features}

The monochromator system studied here consists of three major components: (1) the liquid-gallium pump to provide the coolant flow, (2) the crystal drive mechanism (which provides all the necessary motions) and associated vacuum tank and (3) the crystal assembly. Details of the gallium pump can be obtained in 
reference [3]. The pump used in these tests was made by Qmax Corporation. It is an electromagnetic pump capable of delivering 4 to $5 \mathrm{gpm}$ of liquid gallium (at temperatures of about $50^{\circ} \mathrm{C}$ ) at pressures of about $100 \mathrm{psi}$. The liquid gallium is delivered via 0.5 inch teflon tubes with VCR fittings. A bypass valve is available for stopping flow to the crystal while maintaining flow within the pump itself. The crystal drive/vacuum part of the monochromator system used in these tests was built by Kohzu-Seiki, Japan, and will hence be referred to as the Kohzu monochromator. Details can be found in reference [4]. It essentially consists of an in-vacuum rotation stage driven by a DC servo motor that sits outside the vacuum chamber. Vacuum is maintained by the use of magnetic seals. Several other translation and rotation stages are mounted on the main rotation stage in vacuum. These use in-vacuum motors, and thus only electrical feedthroughs are necessary. The crystal sits inside the vacuum chamber and the coolant for the crystal is fed through the shaft of the main rotation. A general view of the setup is shown in figure 1. For these tests, the vacuum chamber was opened to air for easier access. The details of the crystal used for these tests are shown in figures 2-5. Coolant flows into the metal manifold, up through a silicon plenum (via 3 holes) and fills the plenum distribution slot, then flows across the slots of the silicon top plate. At the other end of the top plate slots, it is collected by the plenum and flows out the other end of the metal manifold.

A general view of the monochromator system is shown in figure 6. The critical component, the crystal assembly, is shown in figure 7, and schematic diagrams of the cooling-flow loops from the Kohzu monochromator to the crystal are given in figure 8. The normal operating flow loop is configuration $B$, shown in figure 8 . However, most of the tests were conducted under configuration $A$ because that was the original arrangement when the test facility was made available for this program. For the later experiments, the inlet and outlets were switched to create configuration $B$. In this report, all tests were conducted under configuration A unless otherwise noted.

\section{Technical Approach}

Motions that are important to identification of the root cause of the vibration were measured at selected locations. Seven accelerometers (PCB Model 336B) were used in the tests. Different tests, each with a specific purpose, were performed in the Building 362 high bay laboratory:

- Background Excitation: Without cooling flow and other external excitation, acceleration was measured at various locations.

- Natural Frequencies: Important components were tested with a small external impact to excite the natural frequencies. 
- Pumping Excitation: With the pump running but no flow passing through the system, acceleration at different locations was measured.

- Flow Excitation: Acceleration at various locations was measured as a function of flow rate, and effects of temperature and pressure were studied.

- Modifications: With some minor modifications to the system, response at various locations was measured in an attempt to understand the effect of the modifications.

\section{Survey Tests}

Acceleration measured from seven accelerometers was recorded by an analyzer and then integrated twice to obtain displacements. The power spectra of both acceleration and displacement from the accelerometers were recorded for analysis. A key piece of information is RMS displacement at all locations. In all tests, the frequency range considered is 4 to $200 \mathrm{~Hz}$; for frequencies of $<4 \mathrm{~Hz}$, the displacement-time histories are contaminated with integrator noise.

\subsection{Background Excitation}

Floor

Seven accelerometers were placed on the floor along a line about $1 \mathrm{ft}$ west of the supporting table (figure 9). With no excitation, displacement from the seven accelerometers ranged from 0.026 to $0.053 \mu \mathrm{m}$, with an average of $0.04 \mu \mathrm{m}$. Thus, the background excitation from the ambient floor motion is low and is typical of ambient experiment hall floor motion measured at the APS [5]. Exciting the floor by jumping only a few feet away from the accelerometers increased displacement more than 10 times, ranging from $\approx 0.15 \mu \mathrm{m}$ to $0.75 \mu \mathrm{m}$.

Floor and Kohzu Monochromator Table

One of the accelerometers was removed and placed on the top of the Kohzu table at the location T1, shown in figure 9, to measure the motion of the table in the vertical direction. Based on an average of the six accelerometers, the RMS floor displacement is $0.036 \mu \mathrm{m}$, which is close to the previous measurement of $0.04 \mu \mathrm{m}$. The RMS displacement of the table is $0.06 \mu \mathrm{m}$. The motion of the table is larger than that of the floor but remains relatively small. 
Table and Crystal

An accelerometer was placed at each of three locations (T1, T2, and T3 in figure 9) to measure the motion of the table in three orthogonal directions. The remaining accelerometers were placed at the four locations (C1, C2, C3, and C4) indicated in figure 10. Figures $10 \mathrm{a}$ and $10 \mathrm{~b}$ are photographs taken from the east side (looking downstream) and west side (looking upstream) of the table, respectively. In later tests, the accelerometers were moved to locations $\mathrm{B} 1$, U1, and either P1 or P2. The accelerometers at $\mathrm{C} 1, \mathrm{C} 2, \mathrm{C} 3$, and $\mathrm{C} 4$ were intended to measure the motions of the crystal:

T1: On top of the Kohzu table, to measure the motion in the vertical direction.

T2: On the north edge of the Kohzu table, to measure the motion in the north-south (transverse) direction.

T3: On the west edge of the Kohzu table, to measure the motion in the east-west (along the beam or longitudinal) direction.

C1: On top of the west side of the crystal, to measure motion in the vertical direction.

C2: On top of the east side of the crystal, to measure motion in the vertical direction.

C3: On the back of the crystal, to measure motion in approximately a horizontal plane in the south and north (transverse) directions.

C4: On the east end of the crystal, to measure motion of the crystal assembly along the east and west (along the beam or longitudinal) directions.

The displacements were recorded for several periods, $8 \mathrm{sec}$ in each period. Values obtained from the seven locations are given in Table 1. Tests 1 and 2 were performed a few minutes apart, while Tests 3,4 , and 5 were performed the next day.

On the basis of these measurements, we conclude that excitation due to ambient background noise is relatively small. 
Table 1. RMS displacements of table and crystal assembly due to ambient background noise $(\mu \mathrm{m})$

\begin{tabular}{llrrrrr}
\hline Location & Motion & Test 1 & Test 2 & Test 3 & Test 4 & Test 5 \\
\hline C1 & vertical & 0.041 & 0.048 & 0.051 & 0.054 & 0.049 \\
C2 & vertical & 0.037 & 0.033 & 0.031 & 0.044 & 0.040 \\
C3 & transverse & 0.063 & 0.057 & 0.066 & 0.069 & 0.065 \\
C4 & longitudinal & 0.047 & 0.043 & 0.072 & 0.055 & 0.050 \\
T1 & vertical & 0.037 & 0.031 & 0.058 & 0.079 & 0.070 \\
T2 & transverse & 0.048 & 0.045 & 0.068 & 0.062 & 0.064 \\
T3 & longitudinal & 0.066 & 0.060 & 0.054 & 0.055 & 0.052 \\
\hline
\end{tabular}

\subsection{Natural Frequencies of Table and Crystal}

The natural frequencies of the crystal and supporting table were measured to understand the dominant modes. The frequencies were identified from the power spectra of accelerations resulting from a series of small impacts. From the PSD curves, the dominant modes can be identified. Different impacts were used to excite different modes. The following natural frequencies were identified:

Table: $\quad 7 \mathrm{~Hz} \quad$ Up and down (vertical) motion

$35 \mathrm{~Hz}$ North and south (transverse) motion along the the length of the table

Crystal: $\quad 82 \mathrm{~Hz} \quad \mathrm{Up}$ and down (vertical) motion

$122 \mathrm{~Hz}$ East and west (transverse) motion along the axis of the crystal

These are the dominant frequencies that can be identified from the impact tests. The natural frequencies in the other directions for both table and crystal were difficult to excite. Because this test is intended to identify the root cause and not to measure detailed dynamic characteristics of system components, detailed measurements were not performed.

\subsection{Liquid-Gallium Pumping System Excitation}

RMS displacements at the seven locations were measured while the pumping system was operating, but with no flow passing through the monochromator. (The pump was in the by-pass mode, thus, the liquid gallium does not even flow into the Kohzu monochromator.) Displacements are given in Table 2. 
Table 2. RMS displacements of the table and crystal assembly due to pumping system excitation

\begin{tabular}{cc}
\hline Location & RMS Displacements $(\mu \mathrm{m})$ \\
\hline C1 & 0.123 \\
C2 & 0.239 \\
C3 & 0.080 \\
C4 & 0.095 \\
T1 & 0.080 \\
T2 & 0.069 \\
T3 & 0.073 \\
\hline
\end{tabular}

Comparing Table 2 with Table 1 shows that the pumping system excites measurably larger motions. Nevertheless, motions of the supporting table and crystal assembly due to pump excitations remain fairly small.

\subsection{Table Vibration Due to Flow}

In this test, liquid gallium was allowed to flow into the crystal (through the Kohzu monochromator). Table response was measured as a function of flow velocity at locations T1, T2, and T3; results are given in figure 11. In this figure, the response at location $\mathrm{C} 4$ (longitudinal motion of the crystal) is also included for comparison. Vibration of the table is essentially independent of flow rate. The excitation provided by the flow is ineffective in exciting the table vibration. On the contrary, longitudinal motion of the crystal increases with flow rate. This is understandable; because the table, including the monochromator, is relatively heavy, the energy of the excitation source is not sufficient to induce large-amplitude motions.

\subsection{Summary}

On the basis of these scoping tests, it may be concluded that:

- Motions of the crystal assembly due to ambient background noises are fairly small.

- Vibrations of the crystal assembly due to operation of the gallium pumping system, with the flow bypassing the monochromator, are still fairly small. Note that, in this case, the flow totally bypasses the 
Kohzu monochromator (and the crystal, which sits inside the Kohzu monochromator).

- Response of the supporting table to gallium flow is small and is almost independent of flow rate.

- The main excitation source of the crystal assembly is associated with gallium flow.

The subsequent tests were directed to the gallium-flow-induced vibration of the crystal assembly.

\section{Flow-Induced Vibration of Crystal Assembly}

The three accelerometers at locations $\mathrm{T} 1, \mathrm{~T} 2$, and $\mathrm{T} 3$, measuring the motions of the table, were moved to locations $U 1, P 1$, and $B 1$ (see figure 10). Tests were performed for both loop configurations $A$ and $B$, and the accelerometers at these three locations measured the following motions:

U1: Attached to the support of the second crystal, to measure motion along the transverse directions.

B1: Attached to the base of the support of the crystal assembly, to measure motion in the longitudinal directions.

P1: Attached to the nut connecting the $90^{\circ}$ steel angle and Teflon pipe, to measure motion in the horizontal plane approximately in the southeast (horizontal plane, in a direction between longitudinal and transverse) direction.

\subsection{Loop Configuration A}

Because the gallium loop was initially set up in configuration A, extensive tests were conducted for that configuration. In particular, the following series of tests were performed:

A. Accelerations and displacements were measured by decreasing and increasing flow rate.

B. Accelerometers were exchanged at various locations, and tests were repeated.

C. Liquid-gallium temperature was changed, and similar tests were run. 
D. Support conditions of the steel-braided Teflon tubes and crystal assembly were modified, and motion was measured again.

\section{Test A.1: General Response}

Motion was measured as a function of flow rate with increasing and decreasing flow rate. The RMS displacements are given in figure 12; note that figures $12 \mathrm{a}, 12 \mathrm{~b}$, and $12 \mathrm{c}$ are in linear scale, while figure $12 \mathrm{~d}$ is in logarithmic scale. Once the flow rate reaches $\approx 1.6 \mathrm{gpm}$, the RMS displacements at locations $\mathrm{C} 1, \mathrm{C} 2, \mathrm{C} 3$, and $\mathrm{C} 4$ increase dramatically. This can be seen more clearly in Fig. 12d; the slope of the curve to correlate the data from locations $\mathrm{C} 1, \mathrm{C2}, \mathrm{C} 3$, and $\mathrm{C} 4$ will be much larger than 2. This will become more clear from the results of other tests. If the motion of a system with a fixed condition is induced by flow, the response is expected to be proportional to approximately the second power of the flow rate. Note that there is considerable hysteresis in the system.

Test A.2: General Response

This test is the same as Test A.1 with the exception that some of the accelerometers are switched with one another. The results are given in figure 13. It is unclear why the maximum rms displacements differ between Test A1 and Test A2. Nevertheless, the general trend of increased vibrations for flow rates greater than $1.6 \mathrm{gpm}$ is the same in both tests.

Test. A.3: Modifications

To understand the effect of flow and support structures, a series of tests were performed after some minor modifications were made to the crystal assembly. The following symbols are used to designate the conditions:

M1 The outlet portion of the Teflon tube is pushed toward the south (transversely) with a small steel bar to provide additional support.

M2 Both outlet and inlet portions of the Teflon tubes are pushed toward the south with a small steel bar to provide additional support.

M3 A C-clamp is used to secure the 3-point kinematic crystal mount. The position of the clamp is as shown in figure 14 .

M4 A C-clamp is used to secure the 3-point kinematic crystal mount. The position of the clamp is as shown in figure 14 . 
$\mathrm{N}$ Original configuration with no modification.

The tests were performed at $2.38 \mathrm{gpm}$ and $50^{\circ} \mathrm{C}$. Results are given in Table 3 .

Table 3. RMS displacements for various conditions

\begin{tabular}{cccccccc}
\hline & \multicolumn{7}{c}{ Location } \\
\cline { 2 - 8 } Test Conditions & C1 & C2 & C3 & C4 & U1 & P1 & B1 \\
\hline N & 9.04 & 1.49 & 4.9 & 6.49 & 0.37 & 1.99 & 1.56 \\
M1 & 4.98 & 0.77 & 3.66 & 5.01 & 0.34 & 2.28 & 0.95 \\
M2 & 5.78 & 1.01 & 1.90 & 4.88 & 0.30 & 1.83 & 0.70 \\
M3 & 6.67 & 1.17 & 1.35 & 3.93 & 0.29 & 1.45 & 0.67 \\
M2 + M3 & 5.42 & 1.00 & 2.89 & 2.50 & 0.26 & 1.15 & 0.67 \\
M2 + M4(loosely clamped) & 1.45 & 1.15 & 0.41 & 0.74 & 0.35 & 1.23 & 0.26 \\
M2 + M4(tightly clamped) & 3.17 & 0.94 & 0.45 & 0.84 & 0.45 & 1.69 & 1.86 \\
\hline
\end{tabular}

The effects of the minor modifications can be determined from Table 3 and are summarized below:

- Pushing the Teflon outlet tube to one side in the transverse direction tends to reduce all vibrations except that at location $P 1$, which is on the outlet connector. The additional curvature of the Teflon tube tends to increase excitation to the connector. Reduction of crystal motion is due to reduction of motion of the pipe with the additional support.

- With the supports to both pipes, except at locations C1 and C2, all other responses are smaller than those when pushing the outlet pipe only.

- With use of the C-clamp, displacements at all locations are reduced relative to displacements under condition $\mathrm{N}$.

- At the crystal, displacements at locations C1, C2, C3, and C4 are significantly reduced when the pipes are supported and the C-clamp is loosely fitted.

These results show that with some minor modifications to the supporting structure of the crystal assembly and Teflon tubes, the crystal vibrations can be changed 
significantly. Therefore, the supporting conditions of the crystal and the Teflon tubes are the critical elements in modifying the system's characteristics.

Test A.4: Effect of Temperature

Acceleration was measured at a flow rate of $2.23 \mathrm{gpm}$ for two liquid-gallium temperatures, $50^{\circ}$ and $57^{\circ} \mathrm{C}$ (two tests in sequence were performed for $57^{\circ} \mathrm{C}$ ). This test was performed following Test A.3 in time with the condition M2. The results are given in Table 4.

Table 4. RMS displacements at different temperatures

\begin{tabular}{cccccccc}
\hline & \multicolumn{7}{c}{ Location } \\
\cline { 2 - 8 } $\begin{array}{c}\text { Temperature } \\
\left({ }^{\circ} \mathrm{C}\right)\end{array}$ & $\mathrm{C} 1$ & $\mathrm{C} 2$ & $\mathrm{C} 3$ & $\mathrm{C} 4$ & $\mathrm{U} 1$ & $\mathrm{P} 1$ & $\mathrm{~B} 1$ \\
\hline 50 & 3.77 & 4.95 & 5.44 & 1.95 & 0.75 & 3.26 & 0.72 \\
$57($ Test 1) & 3.62 & 2.45 & 1.04 & 1.46 & 0.29 & 1.23 & 0.84 \\
57 (Test 2) & 3.91 & 3.08 & 0.71 & 0.96 & 0.36 & 1.56 & 0.69 \\
\hline
\end{tabular}

With higher temperature, fluid viscosity is reduced. At the same flow rate, the response is reduced in general.

Test A.5: Response as a Function of Flow Rate

The motions under modification M2 were measured as a function of flow rate; results are given in figure 15 . Several interesting characteristics are noticed:

- RMS displacements increase monotonically with flow rate at all locations.

- Amplitudes at locations C1 and C2 are approximately the same.

- Displacements at the kinematic mounts of the first crystal, B1, and the second crystal, U1, are fairly small.

- Rate of increase with flow rate increases drastically as the flow rate reaches about $1.8 \mathrm{gpm}$, This flow rate is higher than those shown in figures 12 and 13, where the pipes are not supported by a steel bar.

While the frequency spectra of displacement and acceleration have been considered here, the detailed data are not included in this report. In general, the 
contributions can be divided into two groups: low frequency $(<20 \mathrm{~Hz})$ and high frequency $(>20 \mathrm{~Hz})$. The high-frequency contributions, $>60 \mathrm{~Hz}$, are due to excitation of structural frequencies. RMS displacements of two tests (A.5 and B.1) have also been divided into two groups, 4 to $20 \mathrm{~Hz}$ and 20 to $200 \mathrm{~Hz}$. The RMS values of Test A.5 are shown in figures 16 and 17.

Comparing figs. 15 and 16, it is obvious that the motions are due essentially to low-frequency contributions. The high-frequency contributions are very small.

Test A.6: Repeatability of General Response

The response measured at different times under the same conditions may be different. For example, under condition M2 described in Test A.3, the results shown in Table 5 were obtained at different times.

Table 5. RMS Displacement (Test A.6) under condition M2 of Test A.4 $(\mu \mathrm{m})$

\begin{tabular}{rrrrrrrr}
\hline Test & C1 & C2 & C3 & C4 & U1 & P1 & B1 \\
\hline A.6.1 & 5.78 & 1.01 & 1.90 & 4.88 & 0.30 & 1.83 & 0.70 \\
A.6.2 & 6.85 & 1.49 & 1.98 & 3.74 & 0.40 & 1.74 & 0.34 \\
A.6.3 & 5.06 & 1.87 & 2.24 & 3.50 & 0.32 & 2.25 & 0.52 \\
\hline
\end{tabular}

Test A.6.1 was performed first. A clamp was attached to the support of the crystal assembly and then removed. Tests A.6.2 and A.6.3 were performed in sequence after the clamp was removed. Although some variation occurs, none is significant.

\subsection{Loop Configuration B}

In all previous tests, the PZT1 locking plate (figure 18) was tightly connected to the support structure to prevent rotation of the crystal assembly. After all tests with loop configuration A were completed, one end of each of the two Teflon tubes connected to the crystal assembly was switched to set up configuration $B$. Three tests were performed:

Test B.1: General Response with PZT1 Locking Plate Locked

Displacement was measured as a function of flow rate; results are given in figure 19. A comparison of figures 15 and 19 shows that, except for the response at location C4, all RMS displacements in figure 19 are smaller than those in figure 15. This means that loop configuration $B$ provides less excitation to the crystal assembly. A drastic increase in response with flow rate also occurs at about 1.8 gpm. 
The RMS values of this test have also been divided into two groups, 4 to $20 \mathrm{~Hz}$ and 20 to $200 \mathrm{~Hz}$; results are given in figures 20 and 21 .

Test B.2: General Response with PZT1 Locking Plate Unlocked

In all previous tests, the PZT1 locking plate was locked (see figure 18). In this test and in Test B.3, the plate was unlocked. Figure 22 shows the RMS values under this condition. A comparison of figures 19 and 22 shows that releasing the locking plate does not affect the response significantly.

Test B.3: General Response with Unlocked Locking Plate and with Additional Gallium Pressure

In all previous tests, the gallium loop was operated under $\approx 15$ psi of vacuum. In this test, 10 psi of pressure was added to the loop; figure 23 shows the RMS displacements. The effects of the pressure can be seen by comparing figures 22 and 23. Except for the response of the outlet connector at P2, the effects are small.

\section{Assessment of Root Cause and Abatement of Vibration}

Based on the test results, the main excitation source is identified as the gallium flow. It is well understood that flowing fluid is a continuing source of energy that can excite structural vibrations [6]. Once gallium is flowing, the crystal assembly and other components will vibrate continuously. There are several excitation mechanisms:

- Turbulence: The turbulence of gallium passing through the crystal assembly.

- Flow Excitations Associated with Bends and Discontinuities in Pipes: Any bends, as well as discontinuities such as connectors, will induce both steady and unsteady fluid forces.

- Motion-Dependent Fluid Forces: Any pipe motion will induce additional motion-dependent fluid forces such as centrifugal fluid forces and Coriolis forces.

- Cavitation: Fluid noises associated with cavitation will excite structure vibration.

- Fluid Transients: Any fluid transient will be transmitted to the crystal assembly and induce vibration. 
Under certain conditions, all of these mechanisms may exist. Without additional detailed tests or data on flow loops, it is difficult to quantify the effects of each detailed mechanism in this system.

The purpose of this study is to identify the excitation source, which we have determined to be the gallium flow. The next step is to provide some guidelines for alleviating this vibration problem. We can achieve this by assessing the experimental data obtained in this study.

\subsection{Loop Configurations A and B}

The RMS displacements with configuration A are larger than those with configuration $B$. The difference is in the flow path and configuration of the Teflon pipes. In configuration $A$, the Teflon tubes are hung loosely, while in configuration $B$, the Teflon tubes have higher tension and less curvature. The centrifugal forces due to gallium flow in configuration $B$ will be lower than those in configuration $A$. In configuration $A$ at high flow rate, vibration of the Teflon tubes can be seen clearly. This is likely due to the centrifugal force of the gallium flow in the Teflon tubes. The force per unit length acting on the pipe is proportional to $\mathrm{MU}^{2}$, where $\mathrm{M}$ is the mass of gallium inside the pipe and $U$ is the flow velocity. Once the pipe begins to vibrate, additional centrifugal force is induced in the gallium and part of this force is also proportional to $\mathrm{MU}^{2}$. For example, for a straight pipe, there is no centrifugal force; however, once the pipe begins to vibrate, additional fluid forces, $M[(\partial / \partial t)+U(\partial / \partial x)]^{2} y$, are induced, where $t$ is time, $x$ is the axial coordinate of the pipe, and $y$ is the pipe displacement [6]. This force can have several effects: changing the natural frequencies of the pipes, causing instability, and producing nonclassical normal modes. In any case, under configuration $A$, the tube is much less stable. This is why the motions under configuration $A$ are much larger; in this case, vibration of the Teflon tubes is a main excitation source to the crystal assembly.

\subsection{Modifications under Configuration B}

From the RMS displacements of the two groups ( 4 to $20 \mathrm{~Hz}$ and 20 to $200 \mathrm{~Hz}$ ) and power spectra of the displacements and accelerations, it can be concluded that:

- The large motions are associated with the low-frequency contribution $(<20 \mathrm{~Hz})$. For a specific location, when the amplitudes are large, the contribution from the higher frequency range $(>20 \mathrm{~Hz})$ can be ignored. 
- When the supports to the Teflon tubes and the crystal assembly are modified slightly to improve rigidity, the response is reduced significantly and the low-frequency contribution declines.

- At the support, location B1, motion from the low-frequency contribution is much smaller in general

From the test results based on the various modifications in Test A.3, we can conclude that additional supports to the Teflon pipes and supporting plate of the crystal will reduce the response. This means that the supports to the Teflon tubes and crystal assembly can be improved to reduce the vibration amplitudes.

\subsection{Excitation Mechanisms}

It would be useful to determine the excitation mechanisms under various conditions, but this would require a series of detailed studies. At present, however, it is more important to develop a method for eliminating large vibration. Therefore, the key question is why the large motions occur once the flow rate reaches a certain value. Are they due to forced vibration or to dynamic instability? For example, figure 16c shows that when the flow rate is $>1.8 \mathrm{gpm}$, amplitudes are proportional to $\mathrm{U}^{7}$. At flows $<1.8 \mathrm{gpm}$, amplitudes are proportional to $\mathrm{U}^{2}$. Therefore, $1.8 \mathrm{gpm}$ can be considered as the critical flow velocity for Test A.5. If the system is stable, response should be proportional to $\mathrm{U}^{2}$.

The reason for the instability can be explained. When the flow rate is $<1.8 \mathrm{gpm}$, the system is stable; this means that all supports are adequate. The input/output ratio of gallium energy to the crystal assembly does not vary with flow rate. As soon as the flow rate reaches $1.8 \mathrm{gpm}$, the system characteristics change such that the input/output ratio of gallium energy to the crystal assembly varies with flow rate. This means more energy is put into the crystal assembly to cause its large oscillations. The possible mechanisms may be:

- Gallium fluid forces acting on the crystal assembly vary with flow rate. As flow rate increases, the support conditions vary with flow rate, and consequently the system characteristics also change. When the system characteristics change, more energy from the gallium flow will be absorbed by the crystal assembly, resulting in large motion. The change in system characteristics is due to the change of boundary conditions because other parts are fairly rigid and supports are loosely connected.

- Gallium flow inside the crystal assembly may cause large structural motion under certain conditions. 
The cause is probably the change of support conditions due to fluid forces. For example, consider the gallium flow passing through the crystal assembly. Assuming that the inlet area is fixed, this means the input energy is constant (proportional, of course, to $U^{2}$ ). If the outlet area is allowed to move in a certain way, flow energy output may be lower than that of the input. The lost energy will excite the vibration of the crystal assembly. On the other hand, if the outlet is moving in a different pattern, flow energy may not be absorbed by the crystal assembly and instability will not occur.

Based on these considerations, it is obvious that the critical element is support of the crystal assembly. Due to the lack of support rigidity, fluid forces may cause a change in the support condition as the flow rate increases. Because of this change, the gallium flow is a continuing source of energy that causes significant vibration of the crystal.

\section{Conclusions and Recommendations}

The small ambient motions at the crystal assembly, monochromator, and pump always exist. Sources of excitation include ground motion, pumps, gallium flow, and other mechanical sources. Based on this setup, we have identified the main excitation source as the gallium flow. Excitation levels due to other sources are much lower than those of the gallium flow. The most critical elements are the 3point kinematic crystal mount and the flexible tubes connected to the crystal.

The critical portion is the crystal assembly itself. Its vibration level is higher than that at every other location except the tubes themselves. Because the crystal assembly is the most easily changed component, the vibration can be reduced with proper modifications.

The following general guidelines are recommended in the modification of the system to reduce the vibration level:

- Anchor the crystal assembly as rigidly as possible.

- Keep the tubes as smooth as possible, avoid sharp turns, and eliminate discontinuities.

- Anchor the inlet and outlet tubes as rigidly as possible to prevent their vibration. In the flexible portion, reduce the unsupported length.

- Prevent fluid transients and cavitation. 
- Avoid or reduce any flow excitation that excites the crystal assembly directly or indirectly.

Some specific changes can be considered:

- Change the direction of the inlet and outlet so there is no change in flow direction. For example, if both incoming and outgoing gallium flows are in the longitudinal direction without the $90^{\circ}$ turn, the steady fluid forces acting on the support structure are expected to be lower.

- Provide support to the connectors of the flexible tubes so the forces will not be transmitted to the crystal.

- Eliminate the rocking motion (the kinematic crystal mount plate can rotate about the diagonal line $\mathrm{AC}$, see figure 14 with a small force).

- Provide additional support to the flexible tubes.

- Increase rigidity of the supporting structure to the crystal assembly.

Many additional tests can be performed to quantify detailed characteristics of the crystal assembly. However, those are not the objectives of this study. At this time, we recommend that modifications to the support of the crystal assembly and Teflon tubes be considered to avoid degrading crystal performance. Once the new support structures are complete, tests can be conducted again to verify that the vibration of the crystal is within the acceptable level specified by APS under normal flow conditions. 


\section{Acknowledgments}

This work was supported by the US Department of Energy, BES-Materials Science, under Contract No. W-32-109-ENG-38.

\section{References}

1. J. A. Jendrzejczyk, M. W. Wambsganss, and R. K. Smith, "Vibration Response of a Circular Gallium-Cooled Crystal Mirror with Slotted Flow Channels," ANL/MCT/TMS-2 (July 1992).

2. J. A. Jendrzejczyk, M. W. Wambsganss, and R. K. Smith, "Vibration Response of a Rectangular Gallium-Cooled Crystal Mirror with Drilled Flow Channels," ANL/MCT/TMS-3 (Aug. 1992).

3. R. K. Smither, G. A. Forster, C. A. Kot and T. M. Kuzay, Nucl. Instrum. Meth. A266 (1988) 517.

4. Wah-Keat Lee and Dennis Mills, "High Heat Load Monochromator Specifications," ANL/APS/TB-4, Argonne National Laboratory (February 1993)

5. J. A. Jendrzejczyk, M. W. Wambsganss, and R. K. Smith, "General Vibration Monitoring, Experimental Hall," ANL/APS/IN/VIB-93-3 (Jan. 1993).

6. S. S. Chen, "Flow-Induced Vibration of Circular Cylindrical Structures," Hemisphere Publishing Co, New York, NY. 


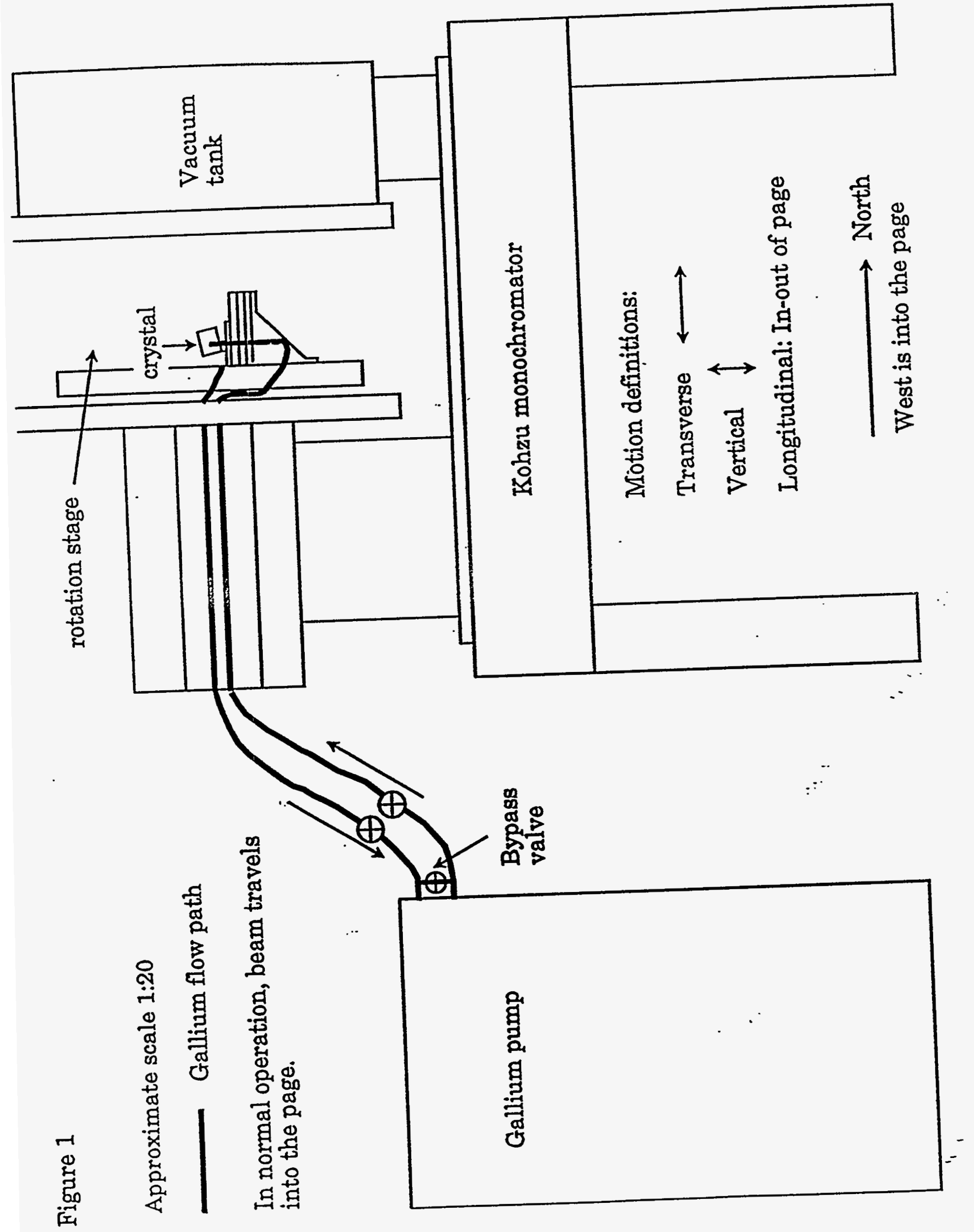


Solld lines denote 'scorlng' .

(blade width, $1 \mathrm{~mm}$ deep)on top face

centered at $10 \mathrm{~mm}$ from edge

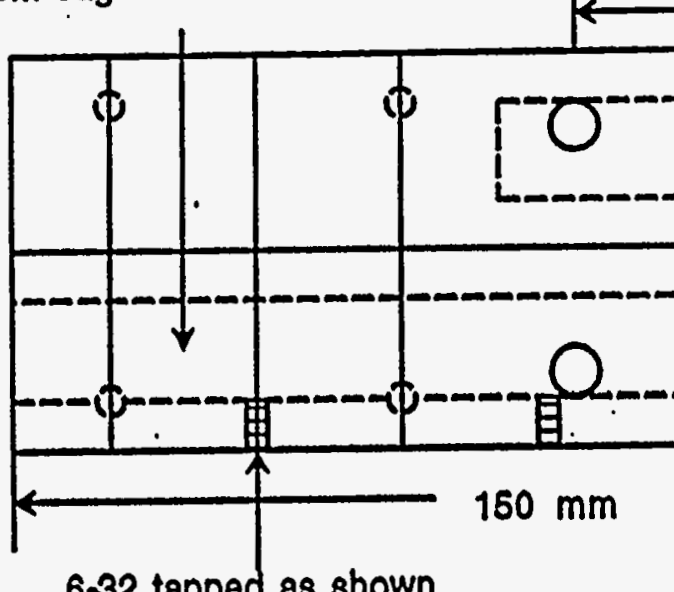

6.32 tapped as shown
$42 \mathrm{~mm}$

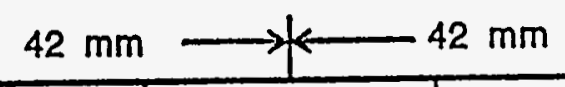

deep enough to penetrate bored hole from end

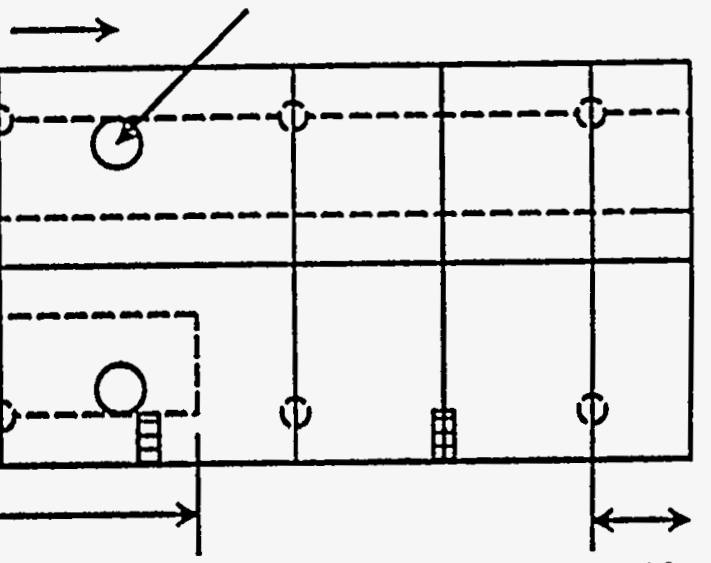

$10 \mathrm{~mm}$

$6 \mathrm{~mm}$
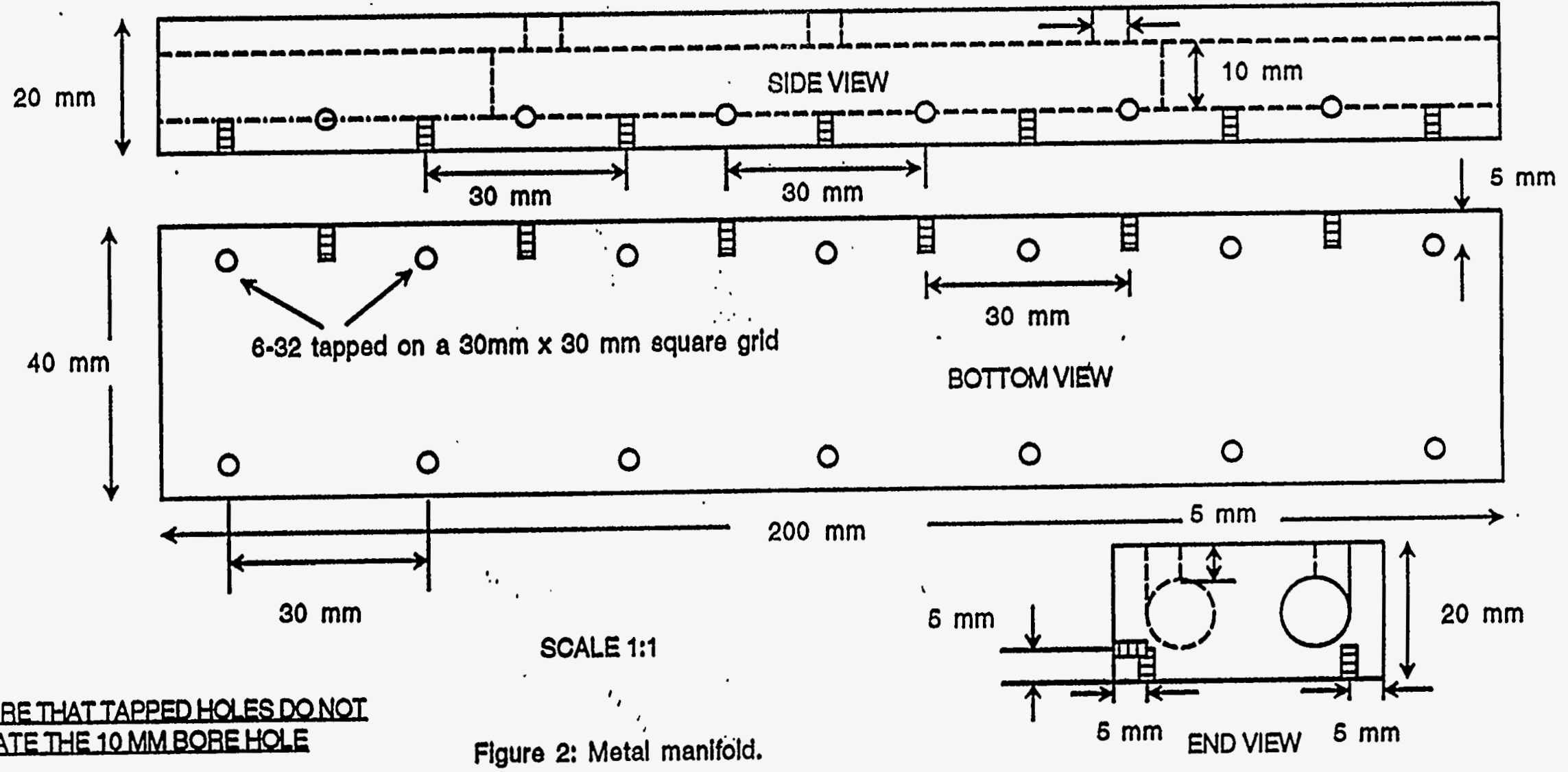

Figure 2: Metal manifold.

\section{PENETRATE THE TOMM BOBEHOLE}


Figure 3: Sillcon plenum

Through holes, $5 \mathrm{~mm}$ diameter

$5 \mathrm{~mm}$ wide, $5 \mathrm{~mm}$ deep trough

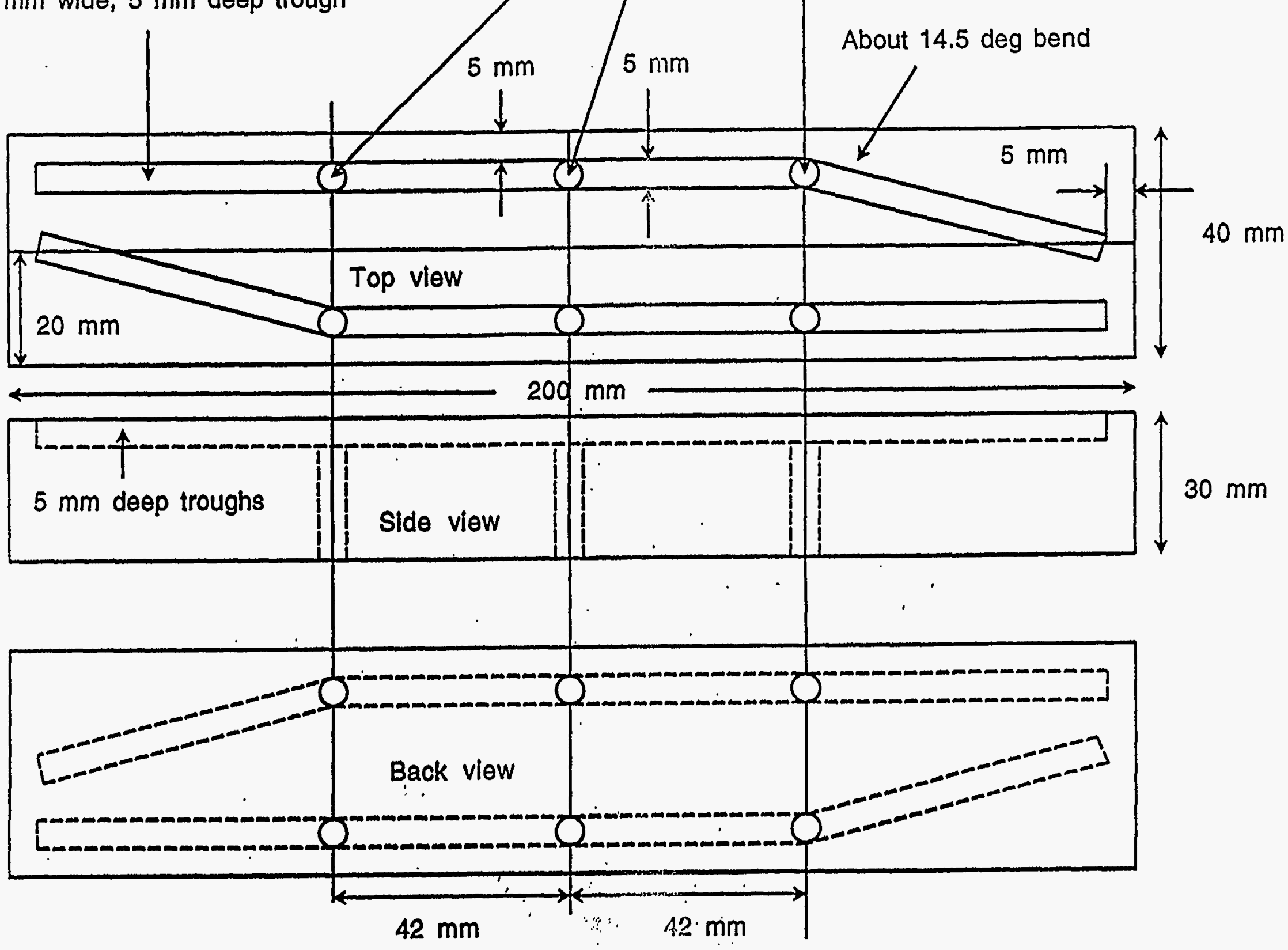



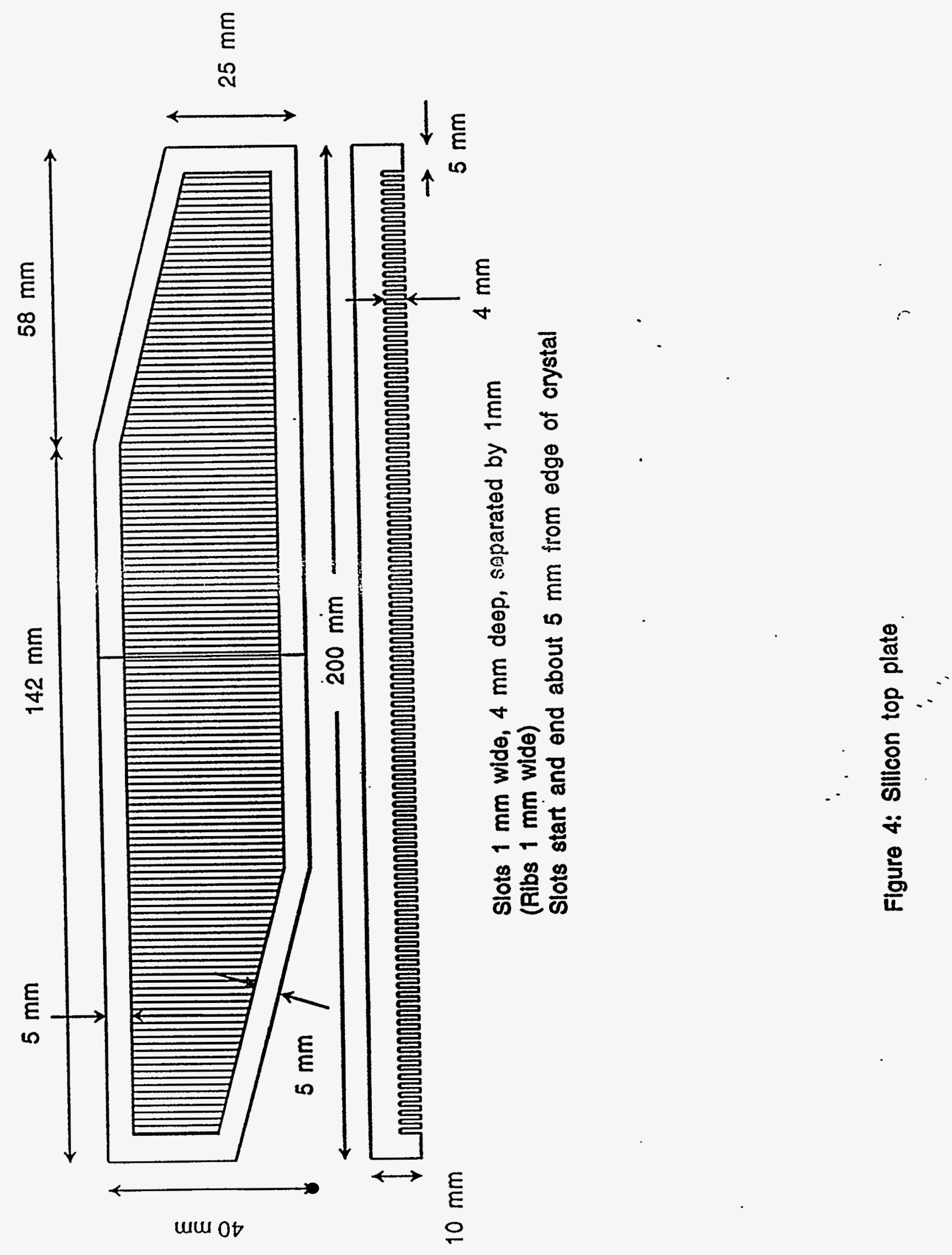


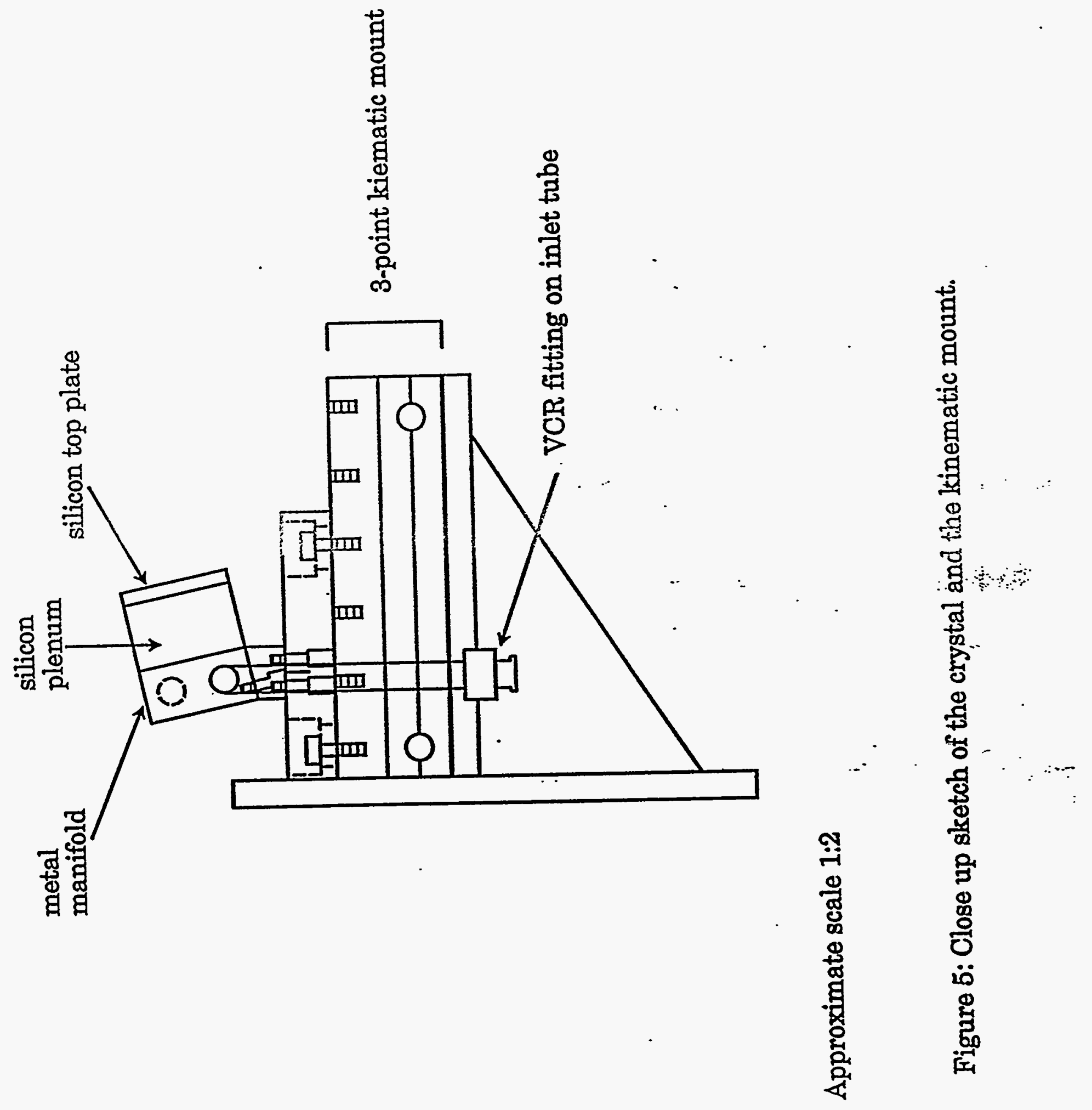




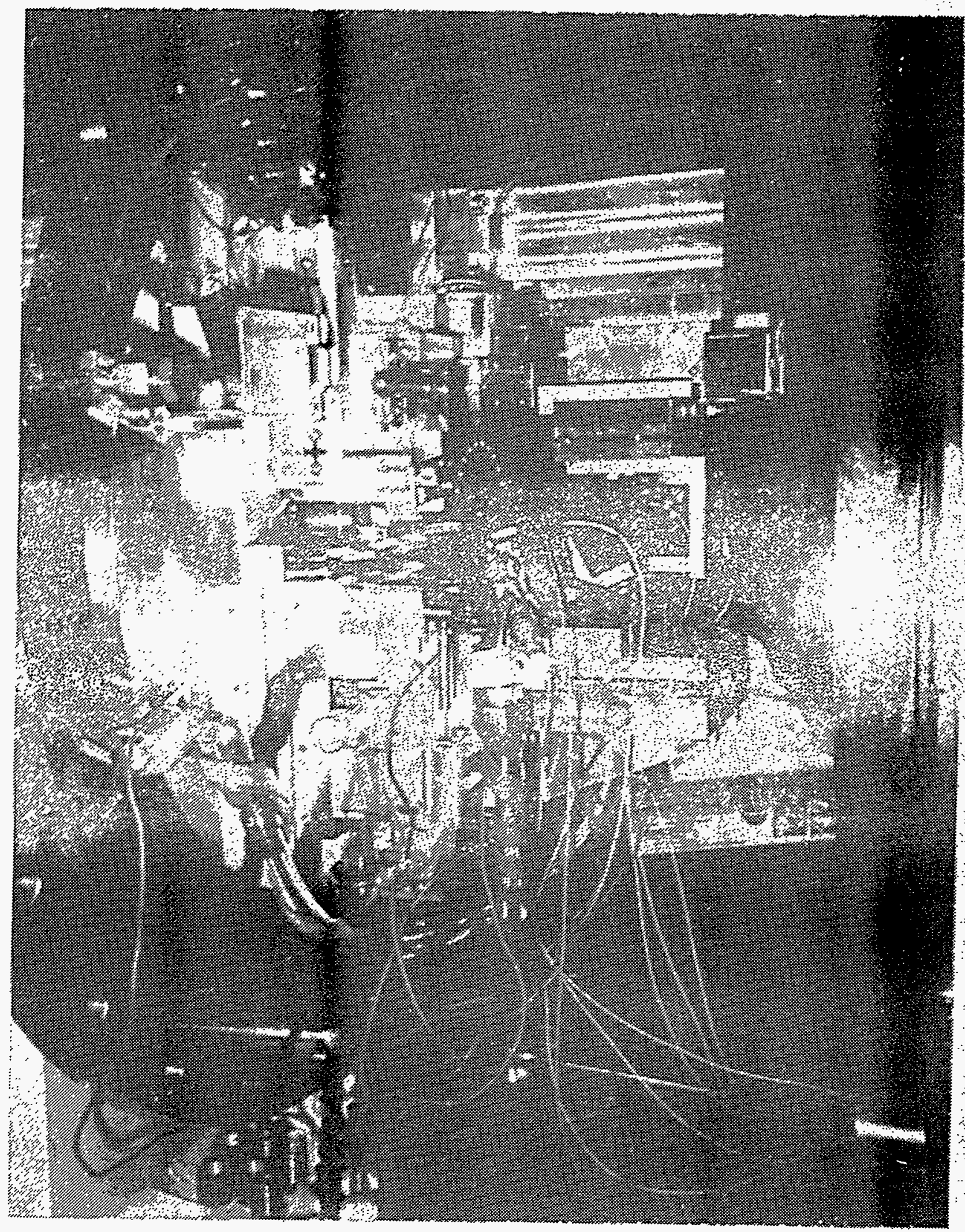

Figure 6. General view of monochromator 


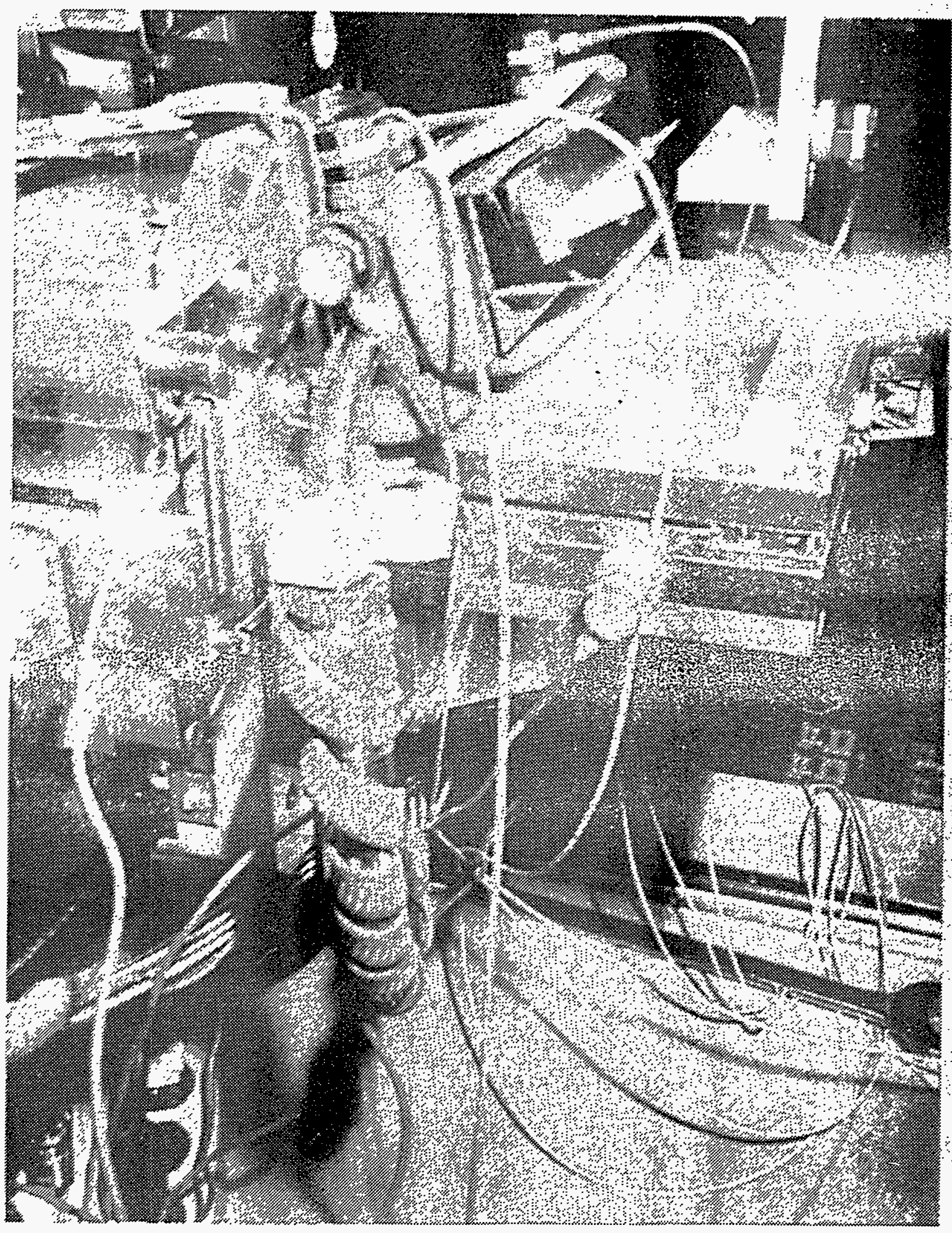

Figure 7. Crystal assembly 


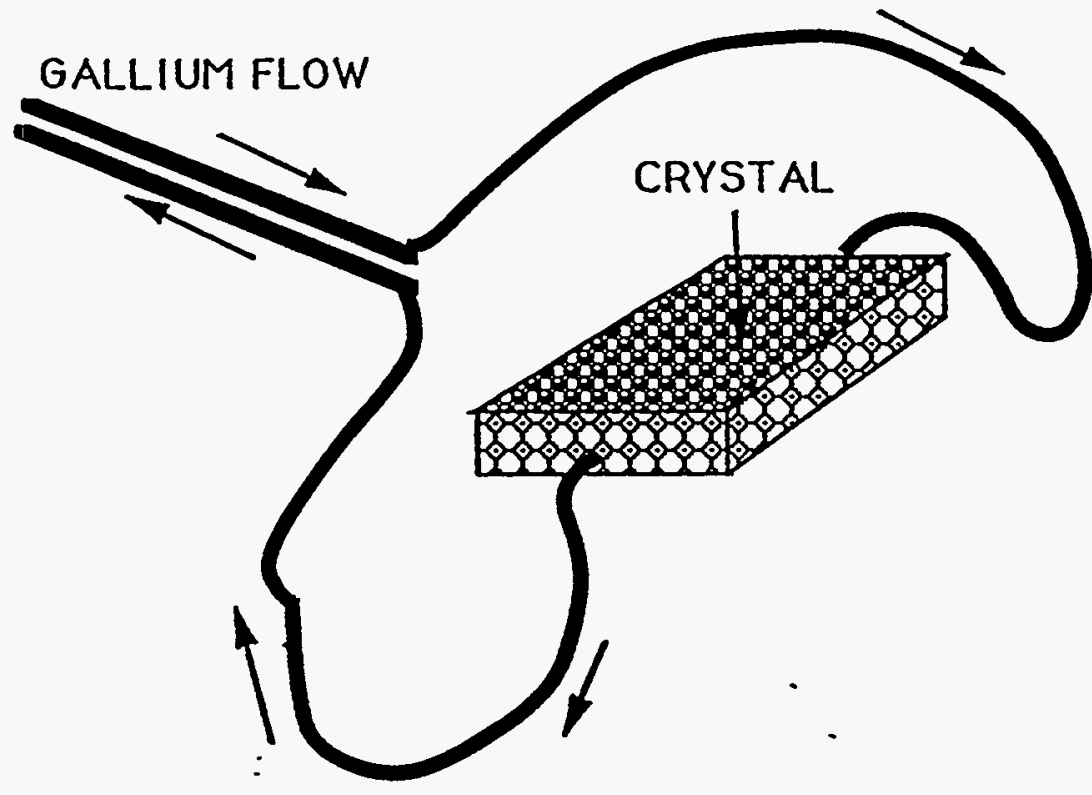

(a) Configuration A

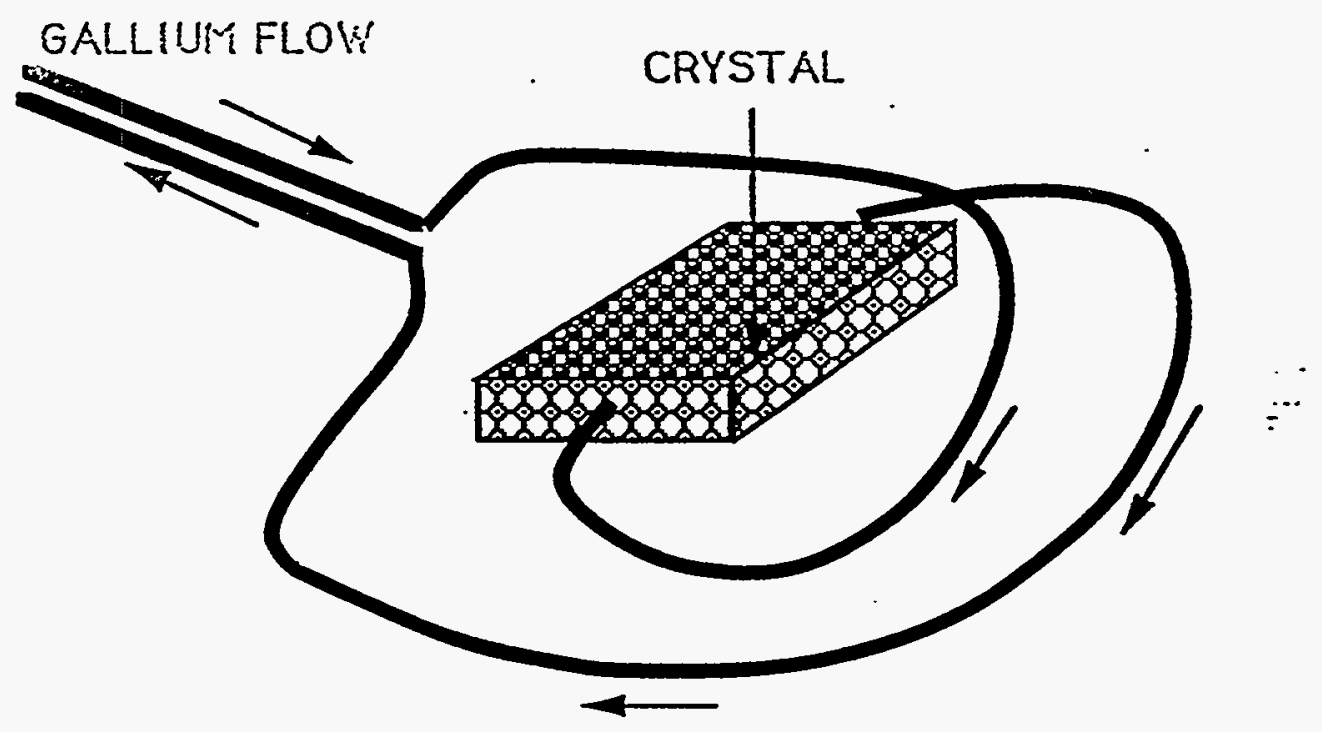

(b) Configuration B

Fig. 8. Gallium loop configurations 


\section{LIQUID GALLIUM}

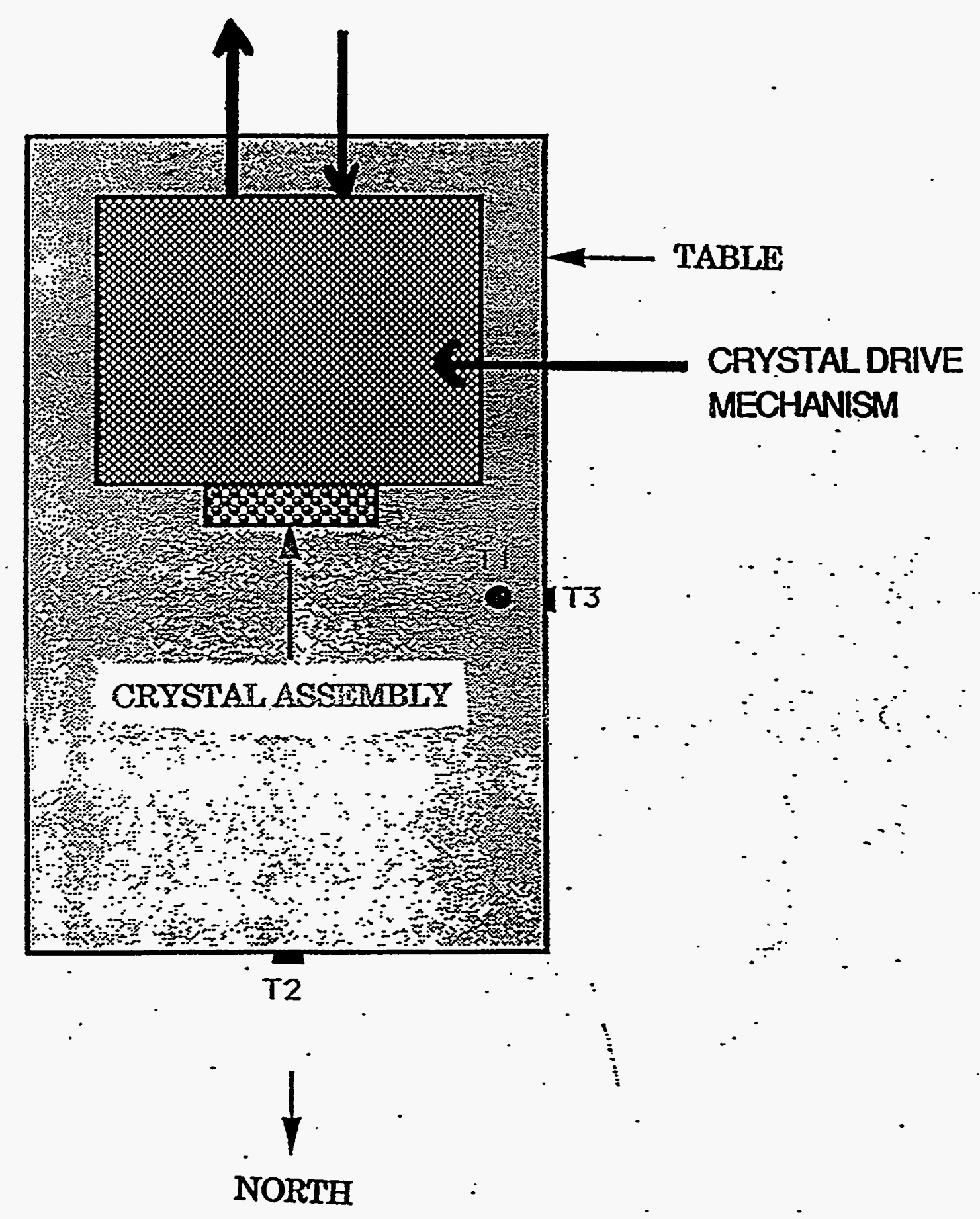

Fig. 9. Top view of supporting table; T1, T2, and T3 are accelerometer locations 


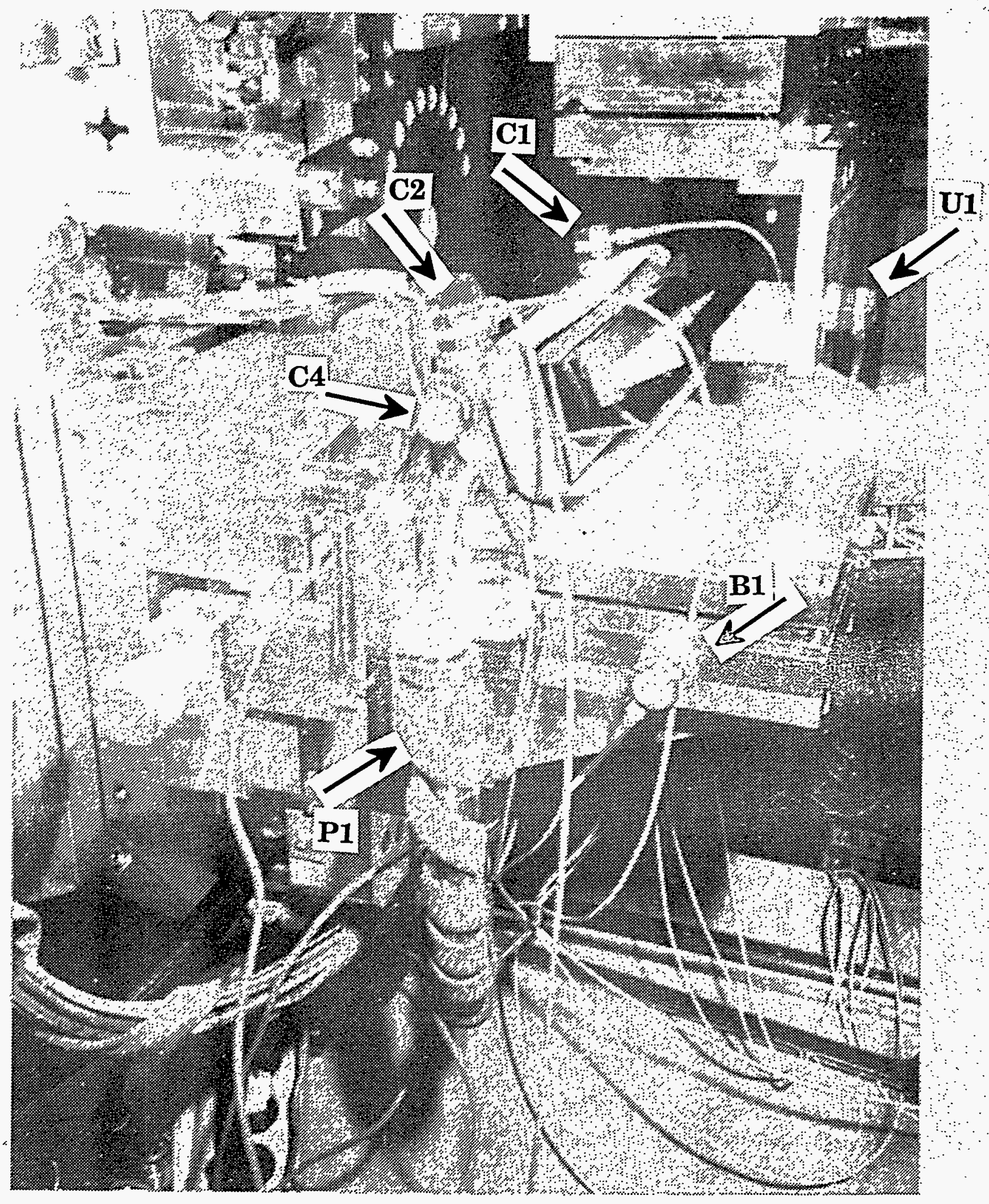

Figure 10. Locations of accelerometers (a) facing west: C1, C2, C4, B1, U1, and $\mathrm{P} 1$; and (b) facing east: $\mathrm{C} 1, \mathrm{C} 2, \mathrm{C} 3$, and $\mathrm{P} 2$ 


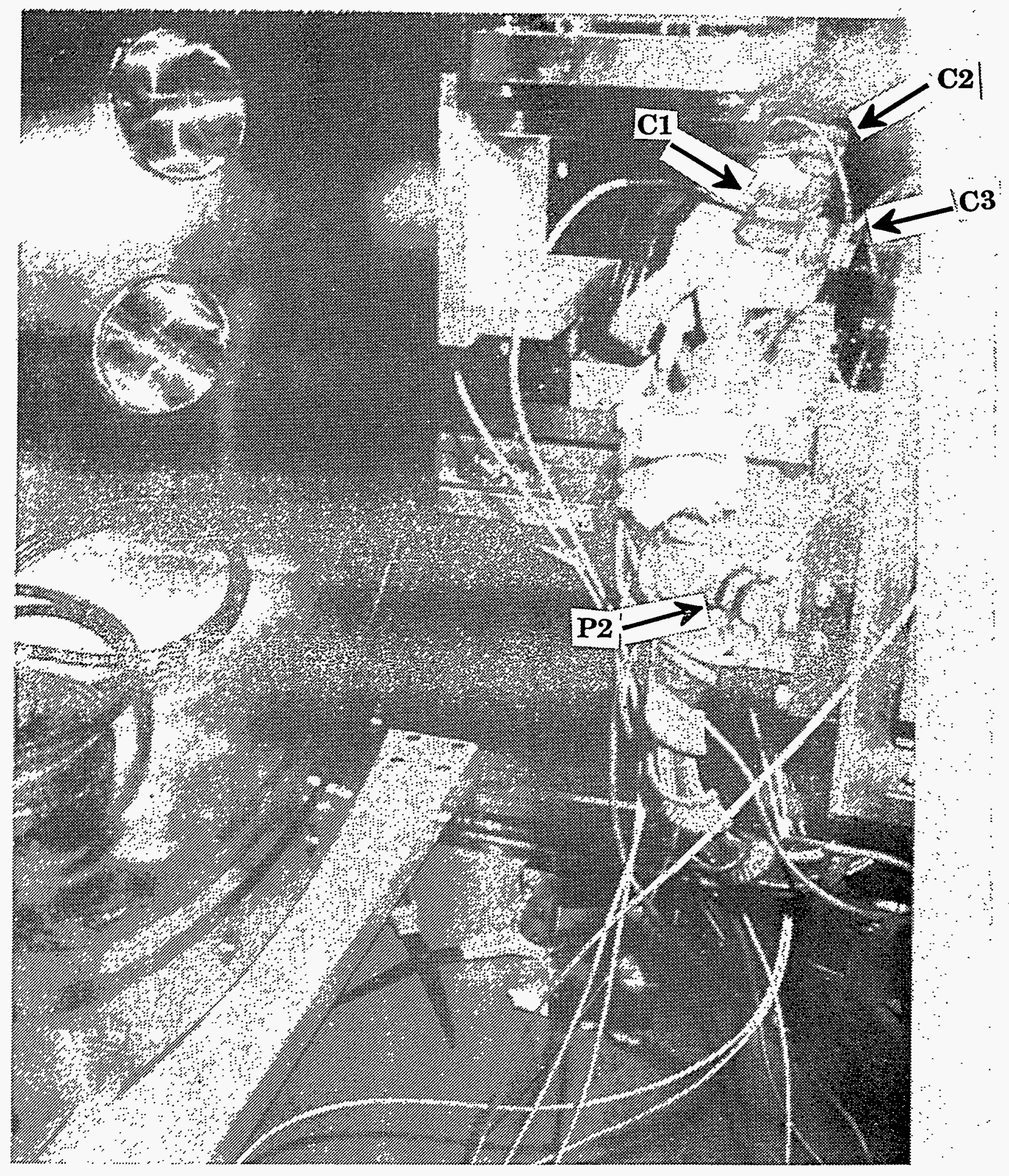

Figure 10. (Cont'd) 


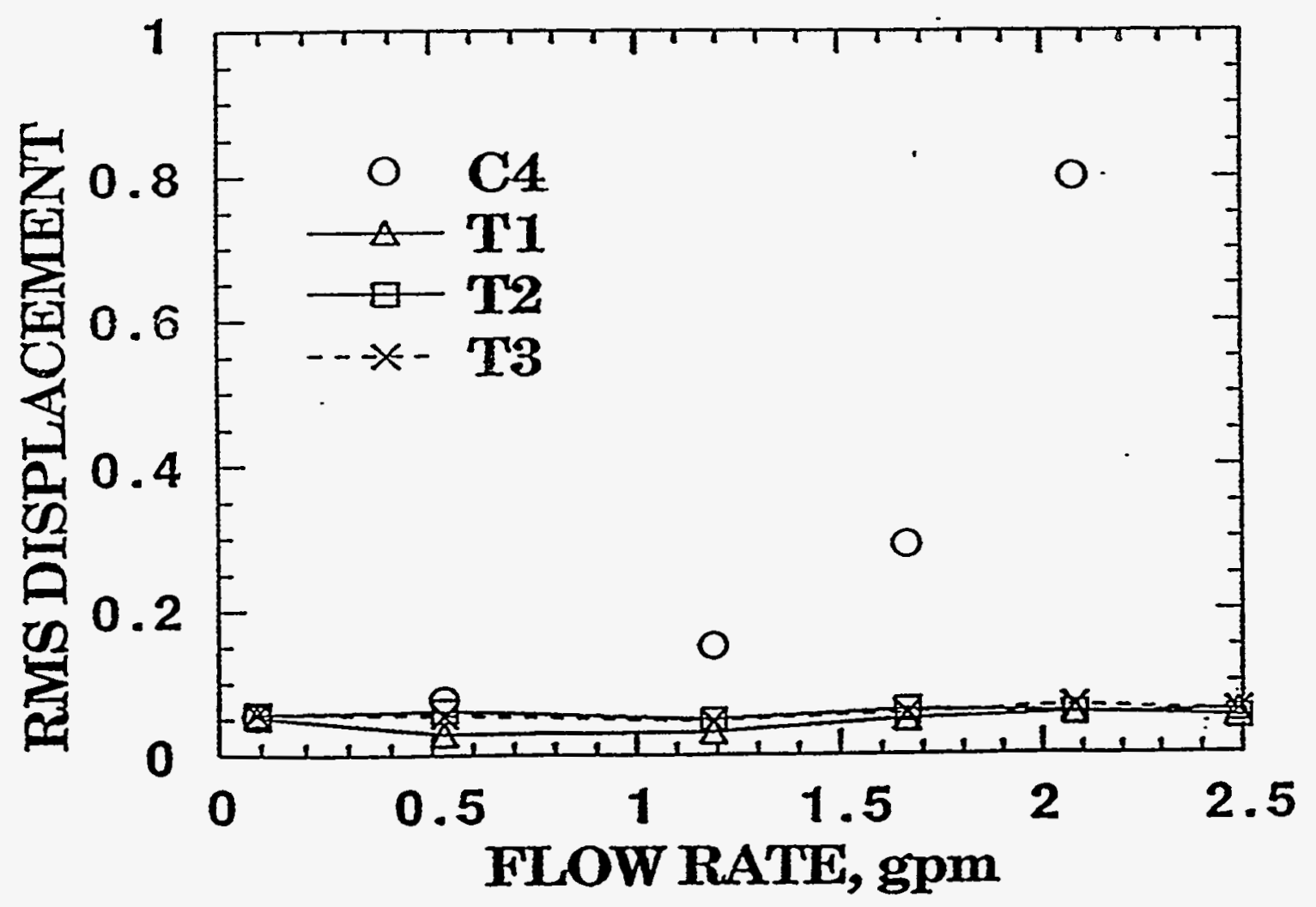

Fig. 11. RMS displacements, C4, T1, T2, and T3; displacement values are in $\mu \mathrm{m}$ 
(a)

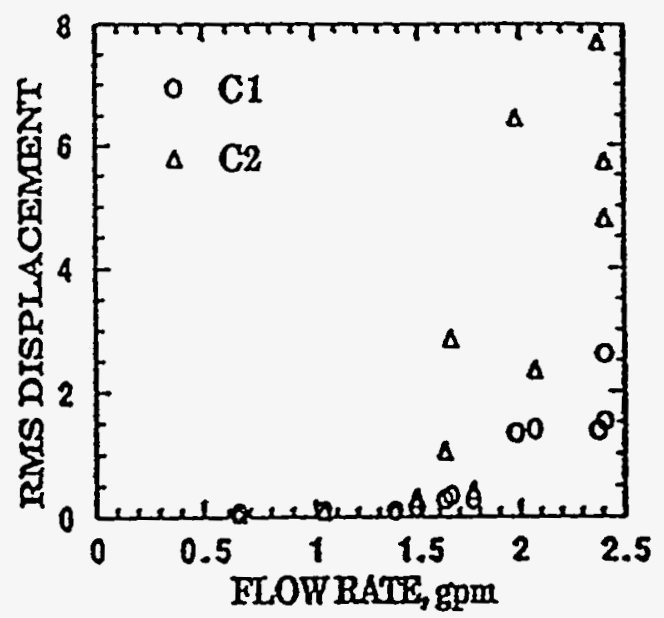

(b)

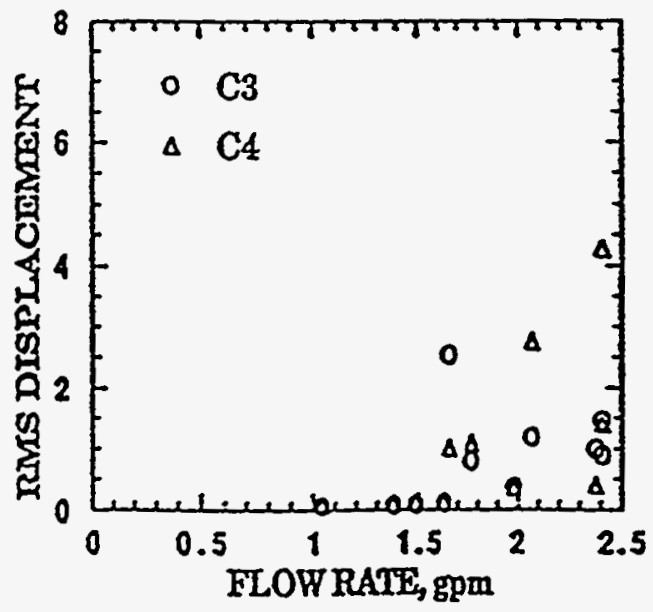

(c)

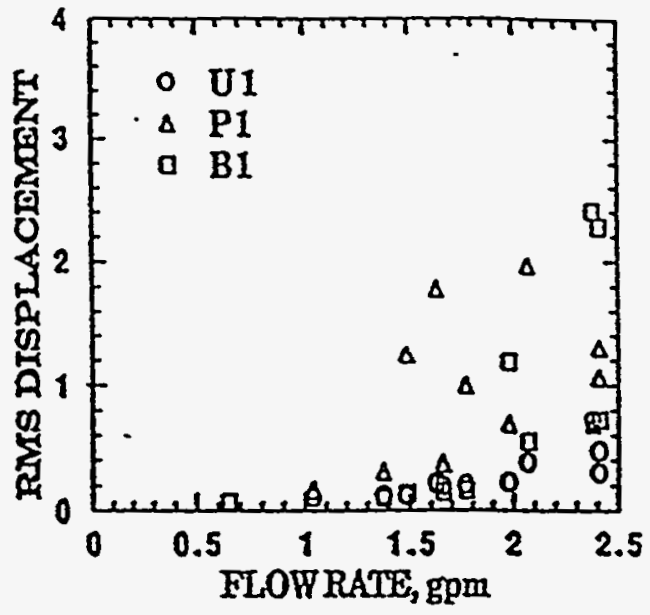

(d)

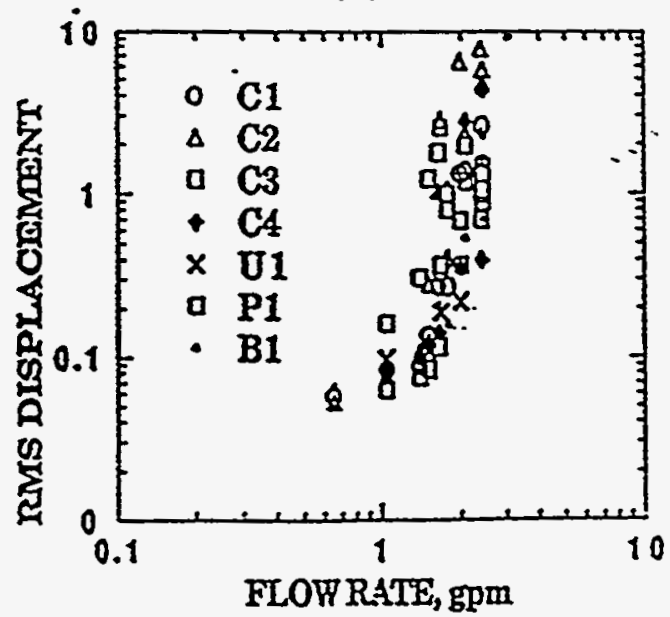

Fig. 12. RMS displacements in Test A.1; all displacement values are in $\mu \mathrm{m}$ 
(a)

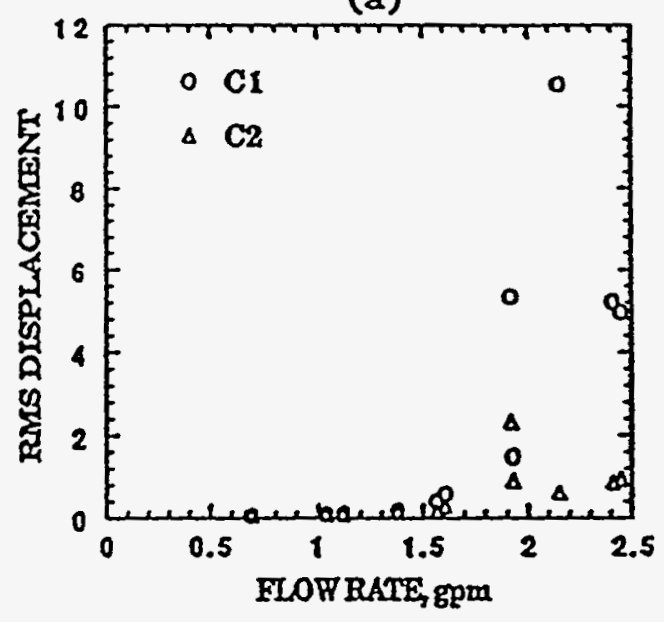

(b)

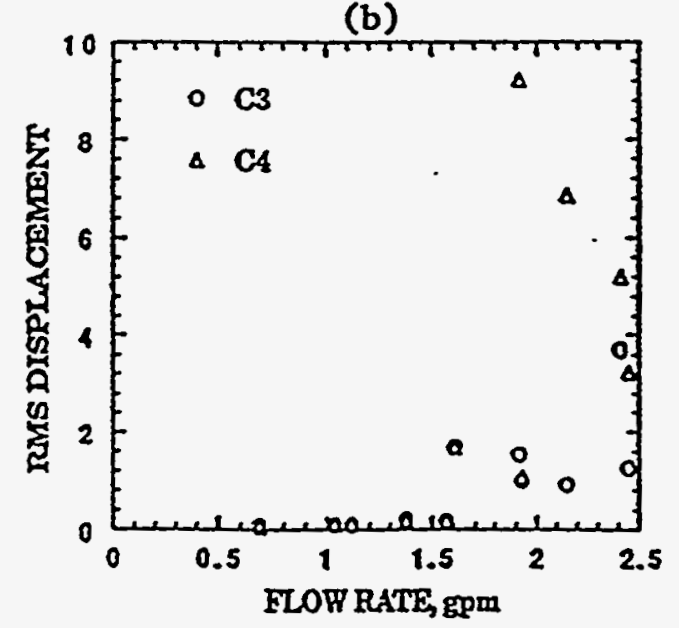

(c)

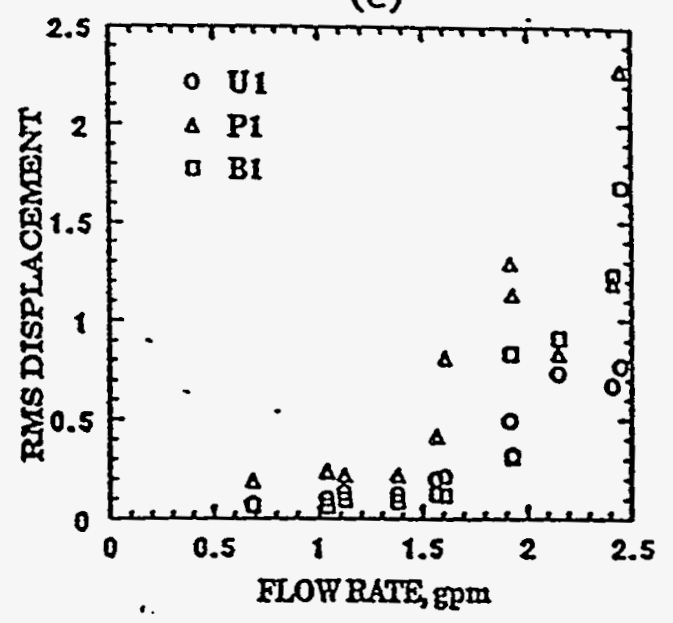

(d)

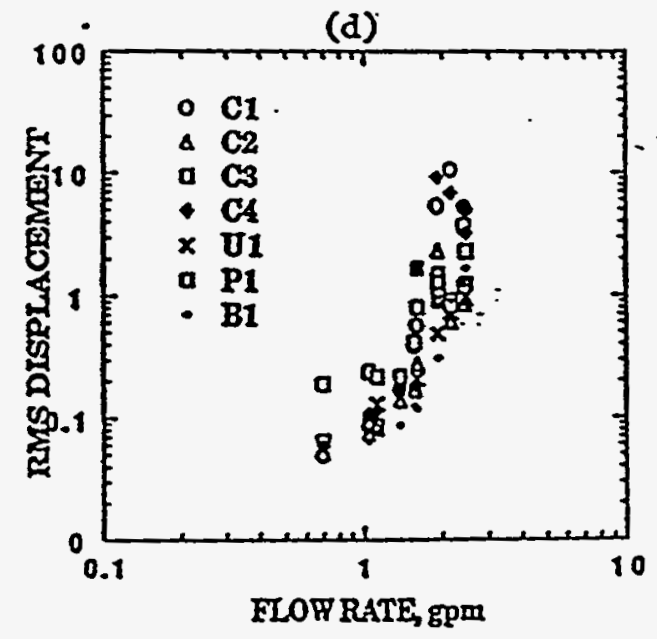

Fig. 13. RMS displacements in Test A.2; all displacement values are in $\mu \mathrm{m}$ 

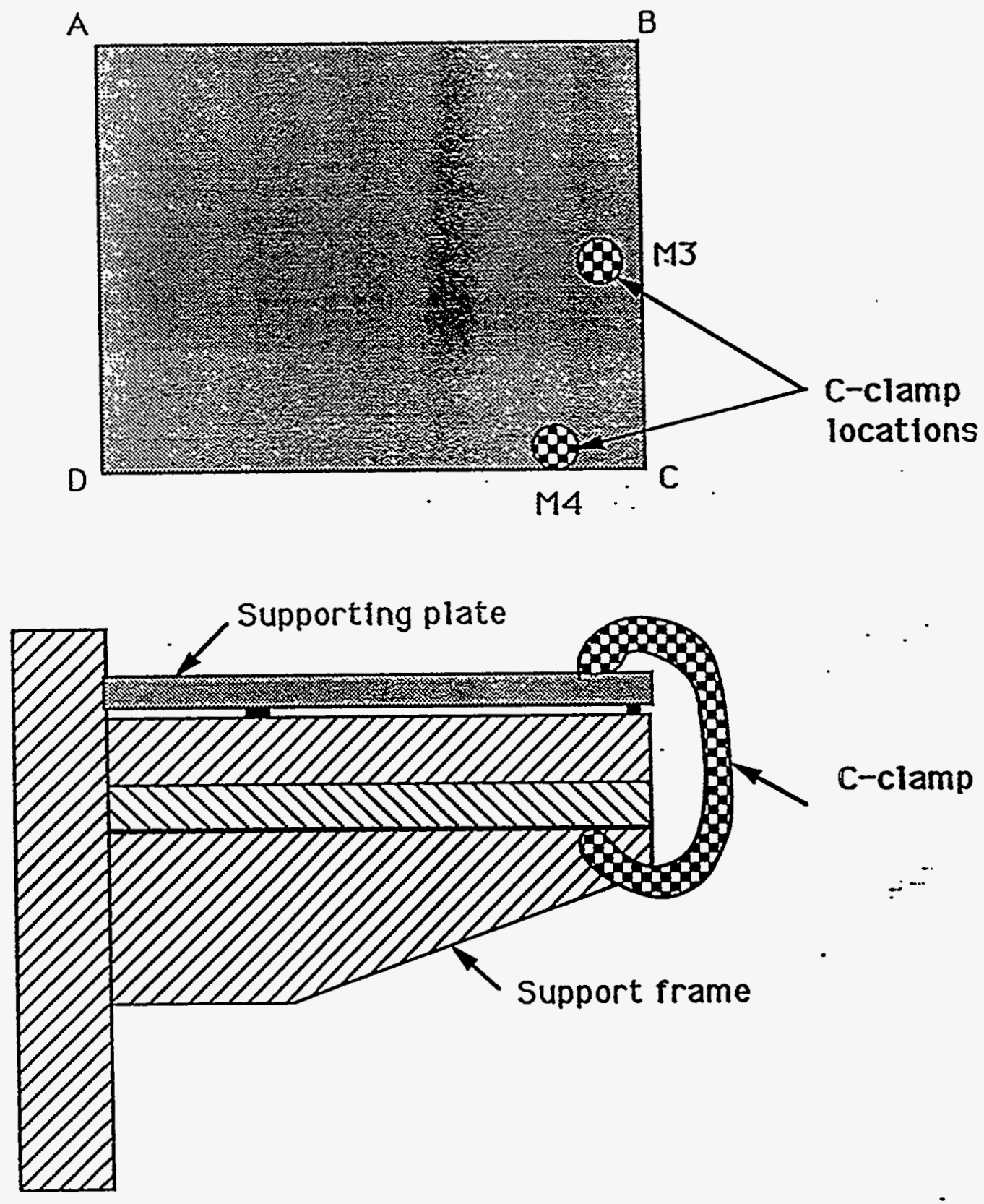

Fig. 14. Sketch of support structure for crystal 
(a)

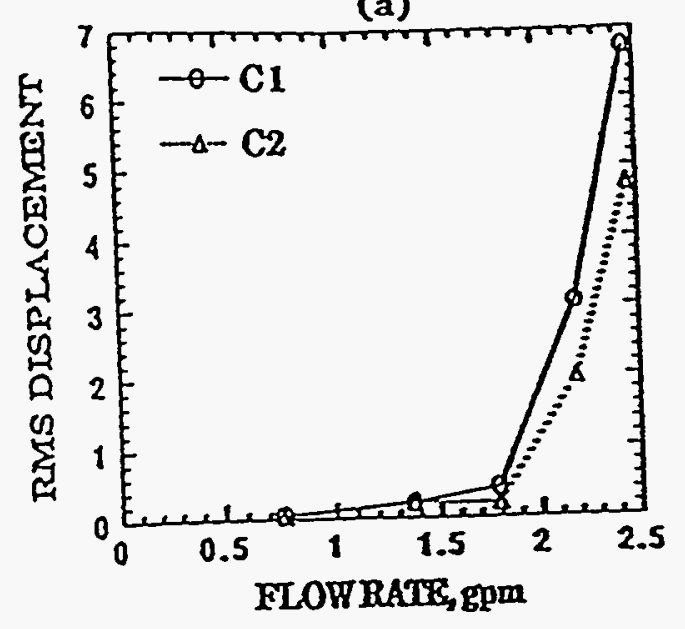

(b)

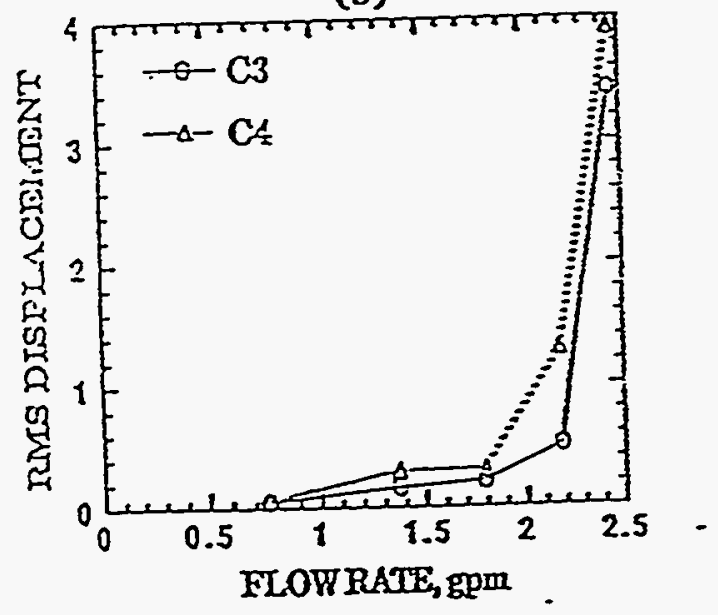

(c)

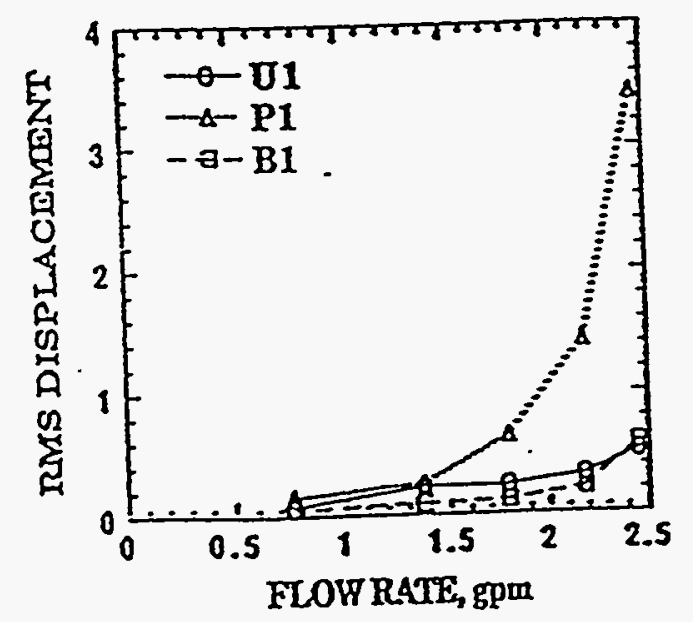

(d)

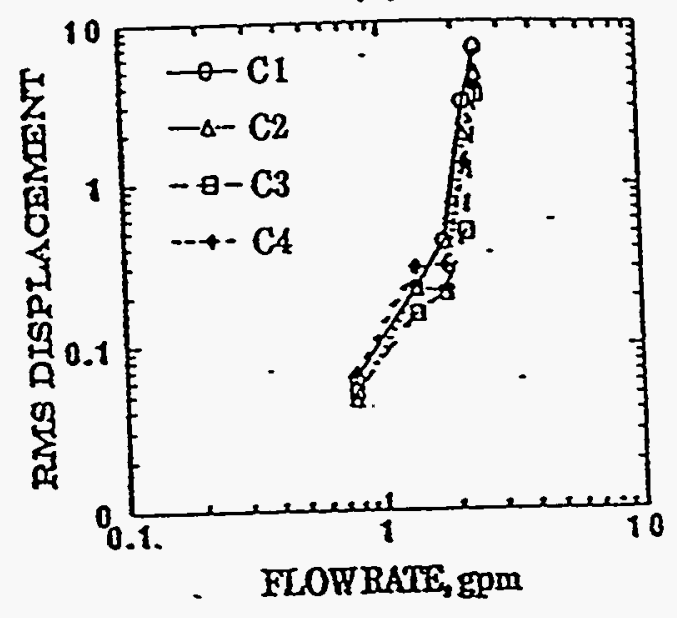

(e)
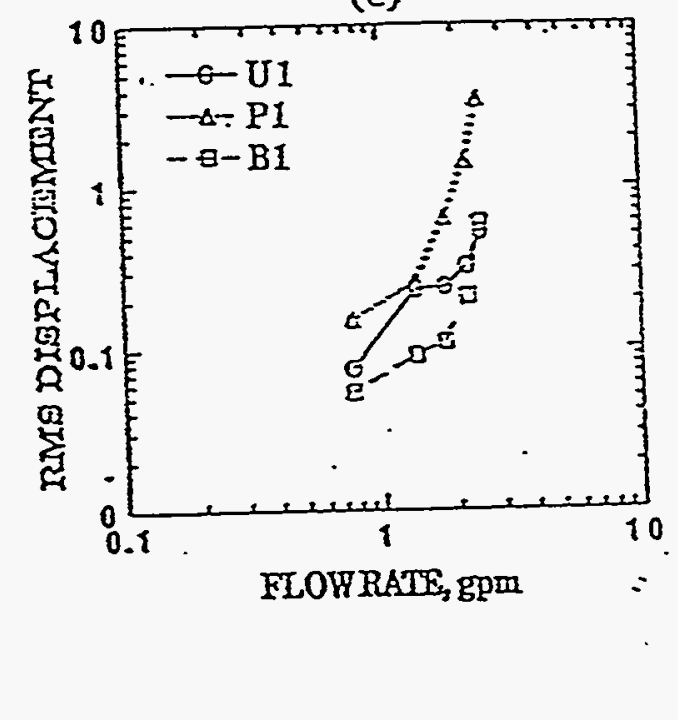
(a)

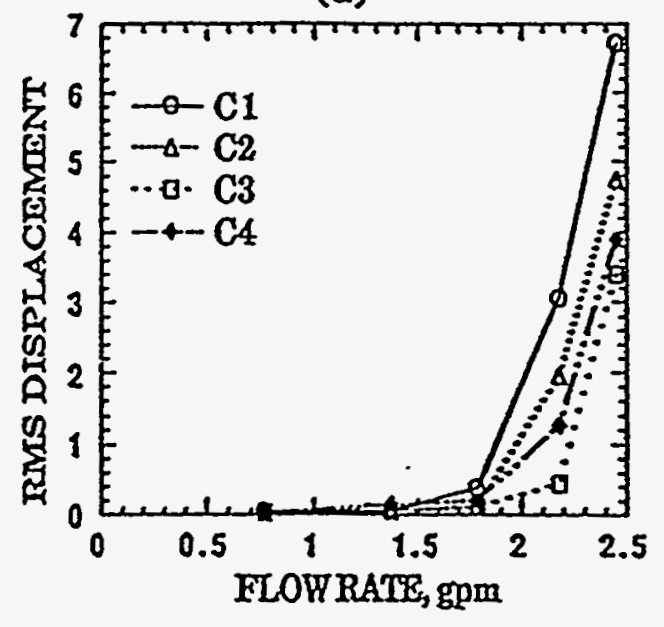

(b)

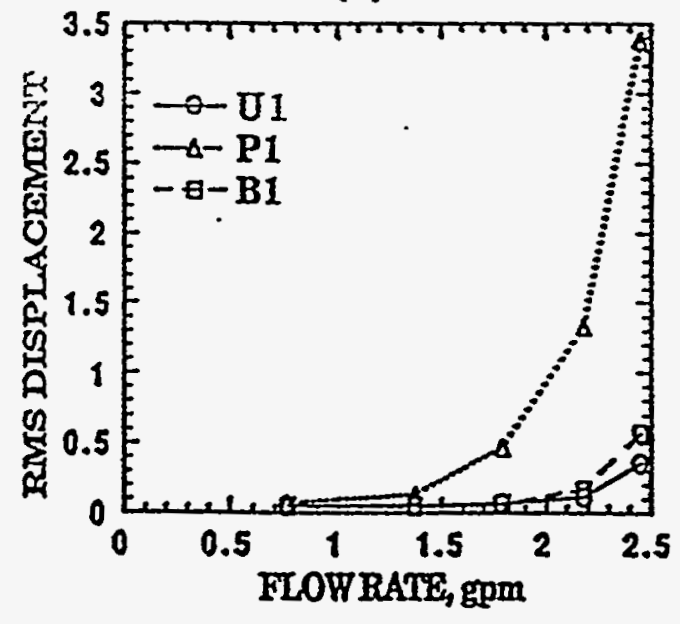

(c)

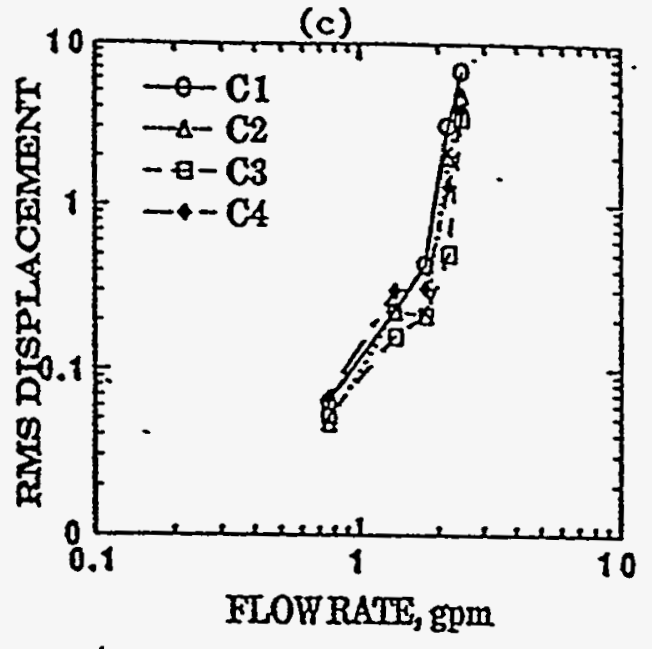

(d)

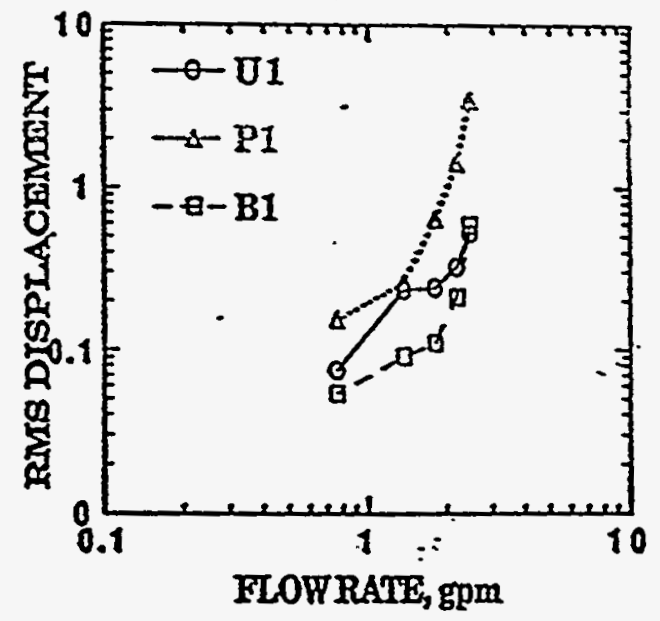

Fig. 16. RMS displacements in Test A.5, 4-20 Hz; all displacement values are in $\mu \mathrm{m}$ 

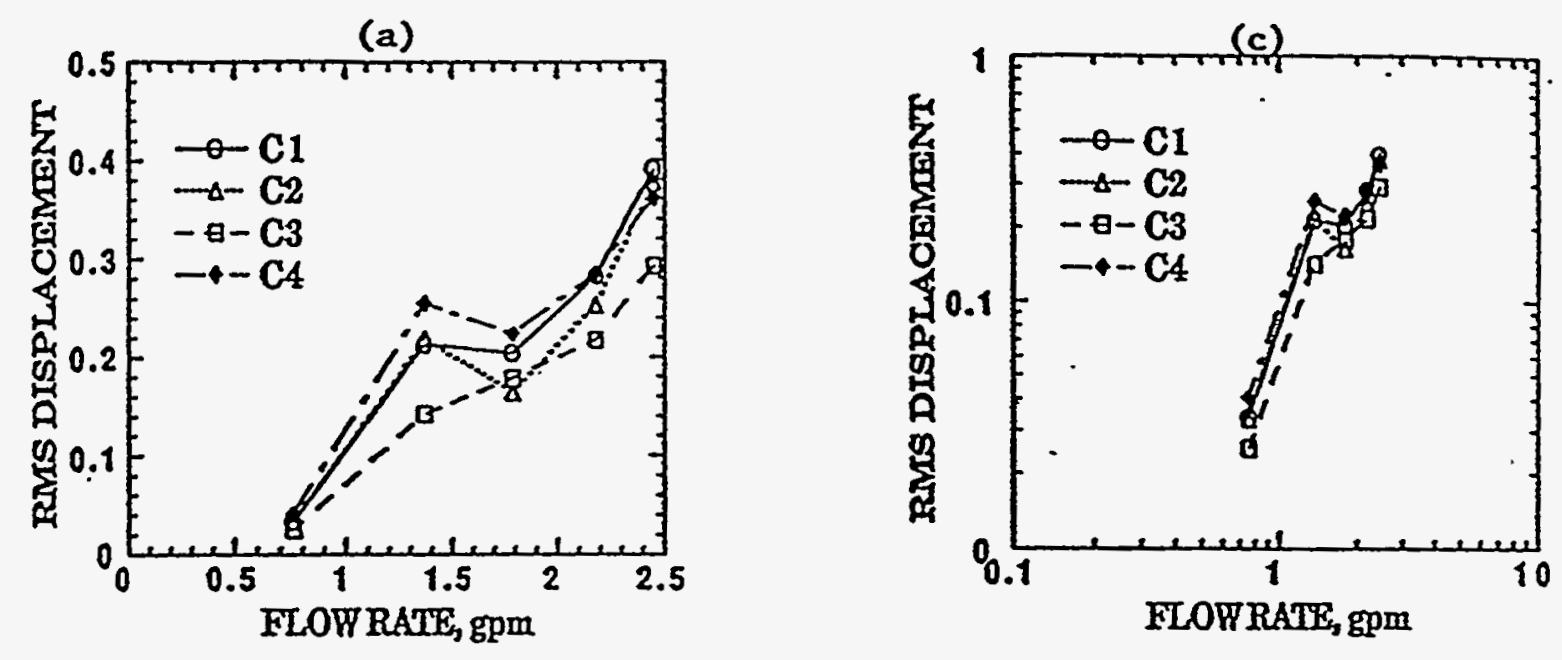

(b)
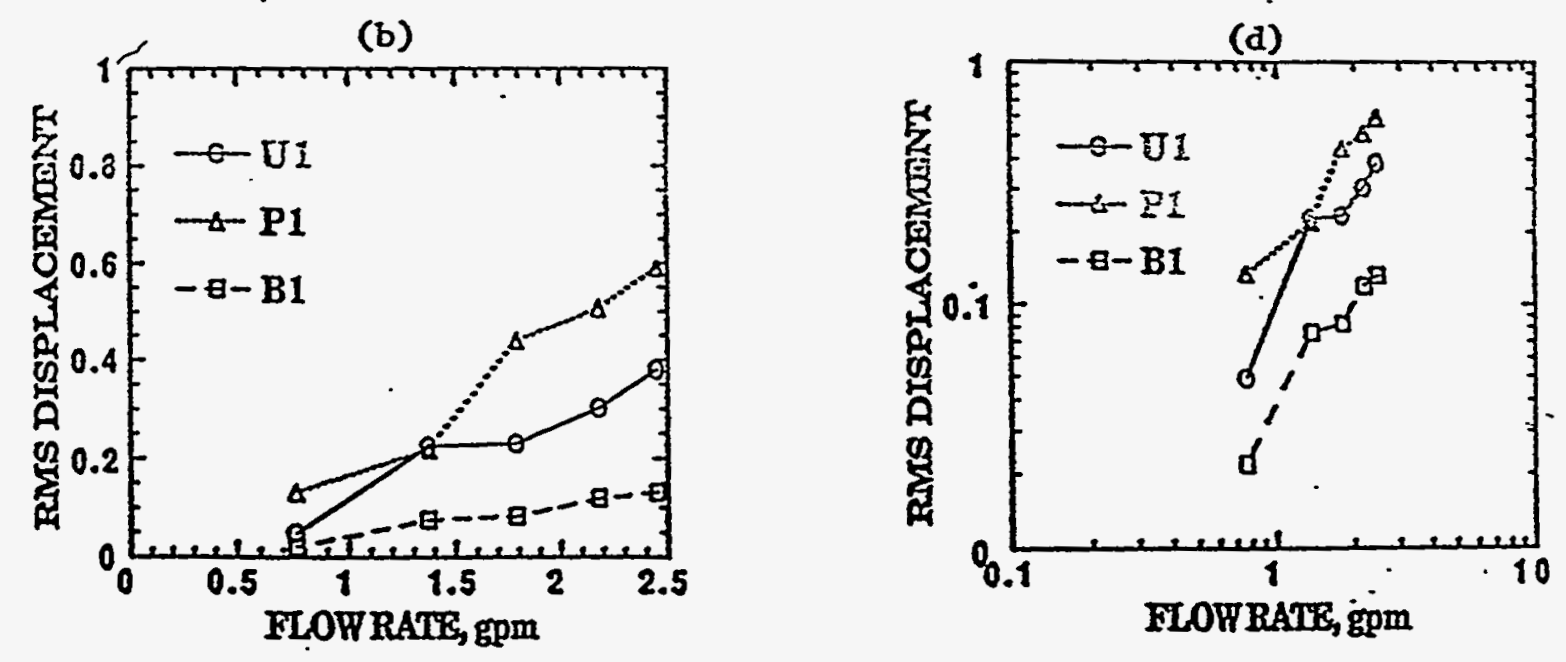

Fig. 17. RMS displacements in Test A.5, 20-200 Hz; all displacement values are in $\mu \mathrm{m}$ 


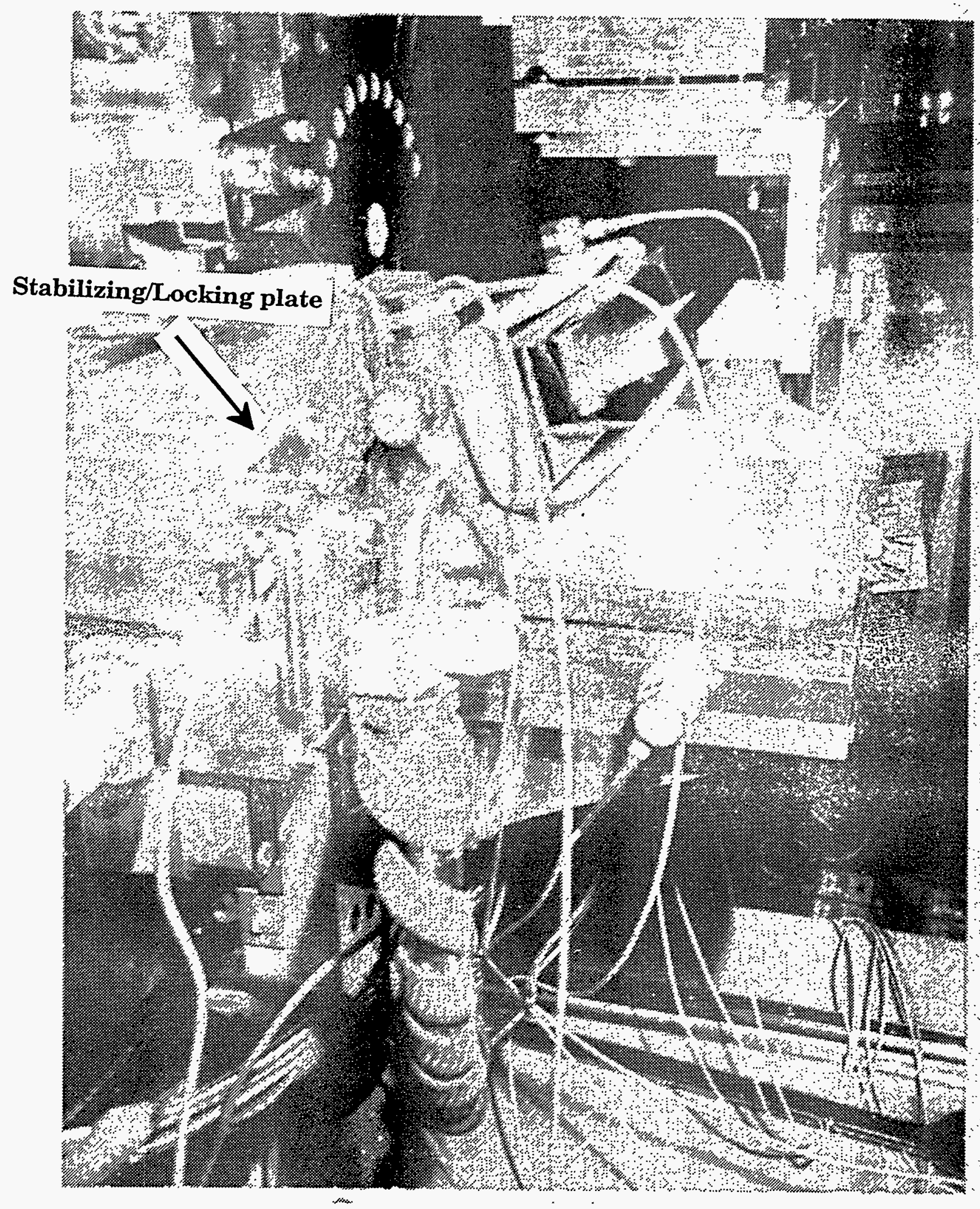

Figure 18. Stabilizing plate 
(a)

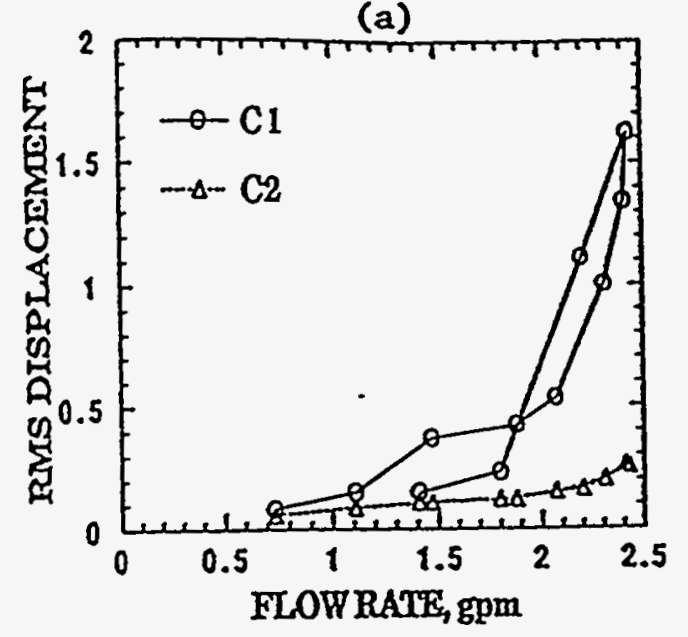

(b)

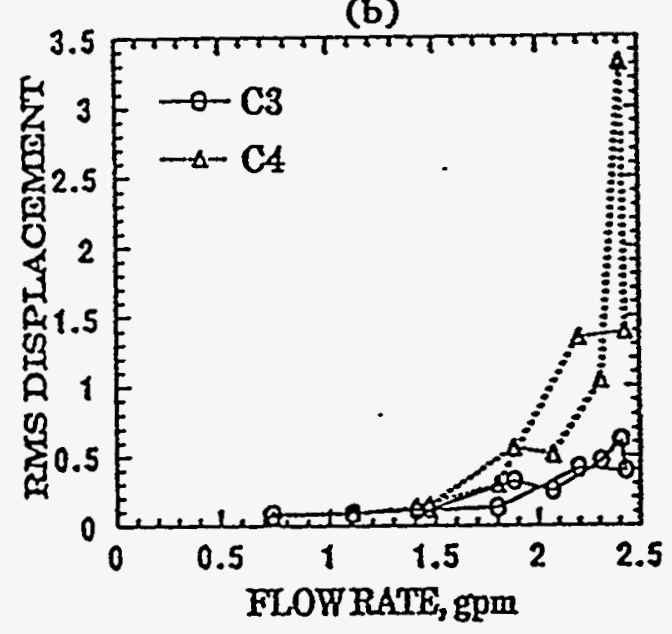

(c)

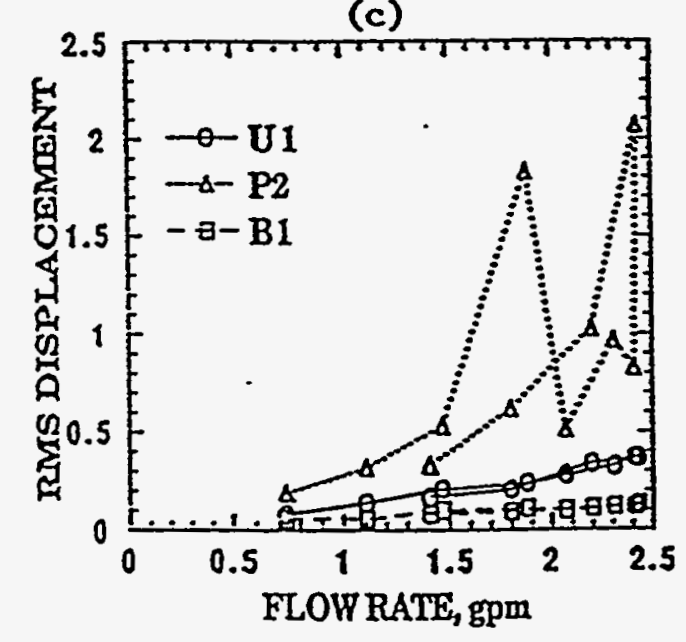

(d)

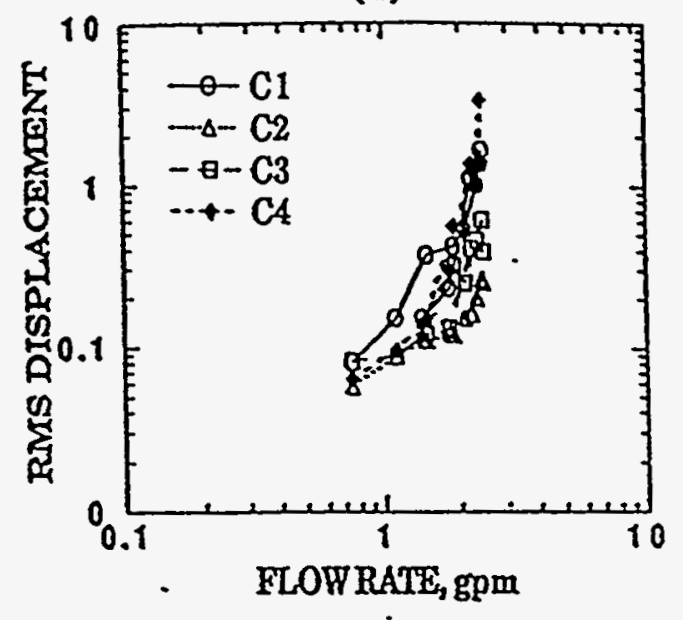

(e)

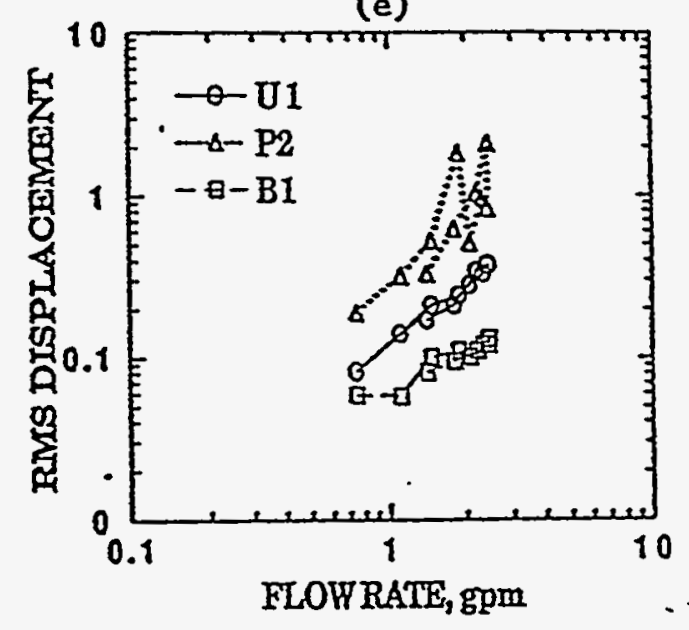

Fig. 19. RMS displacements in Test B.1, 4-200 Hz; all displacement values are in $\mu \mathrm{m}$ 
(a)

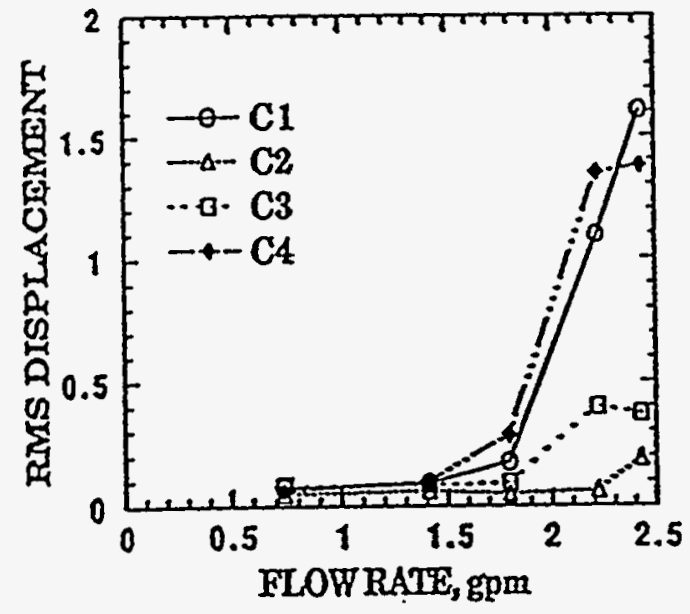

(b)

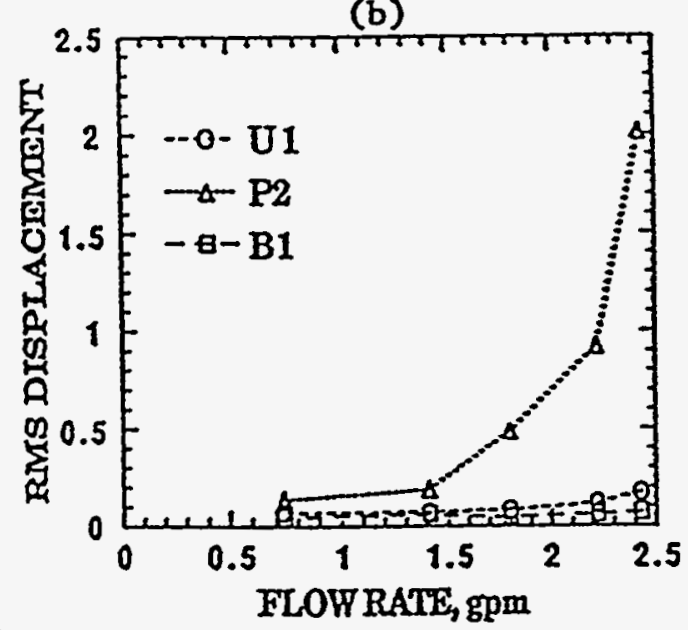

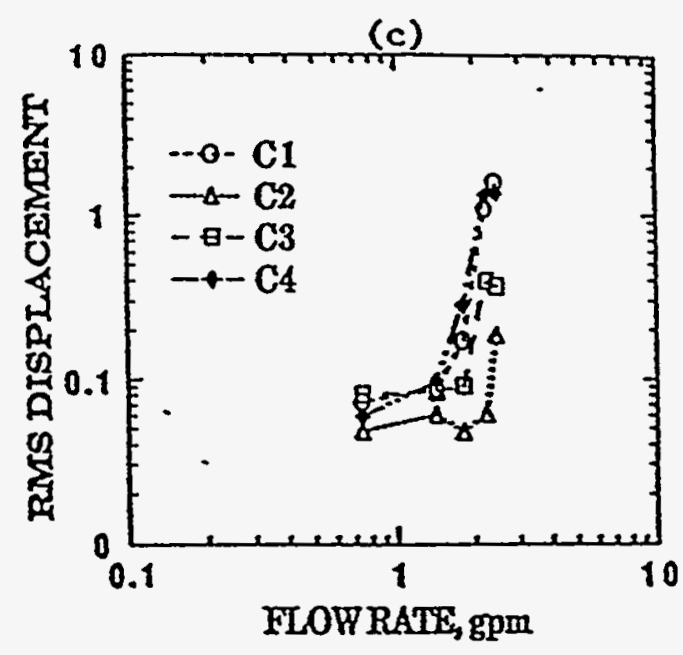

(d)

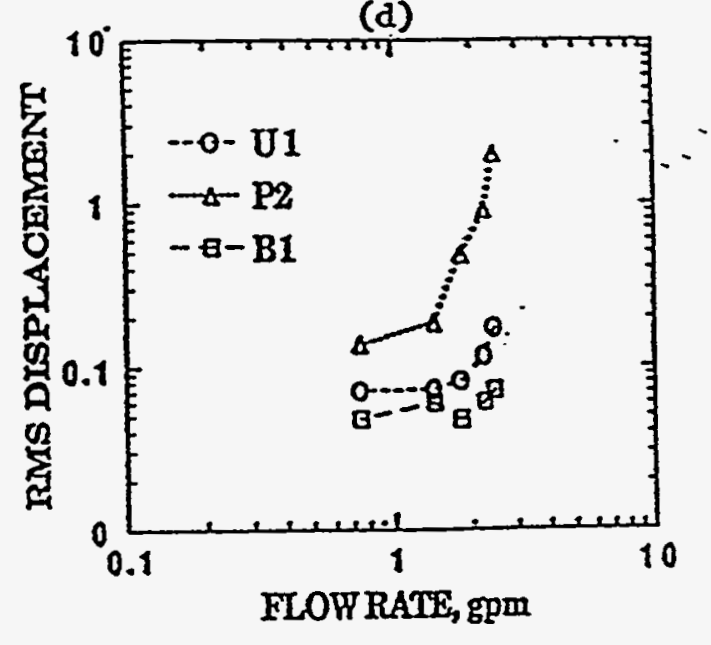

Fig. 20. RMS displacements in Test B.1, 4-20 Hz; all displacement values are in $\mu \mathrm{m}$ 
(a)

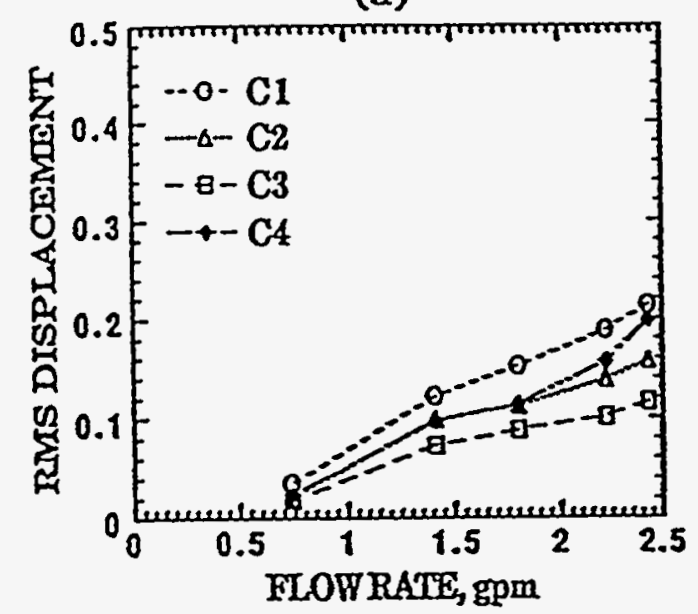

(b)

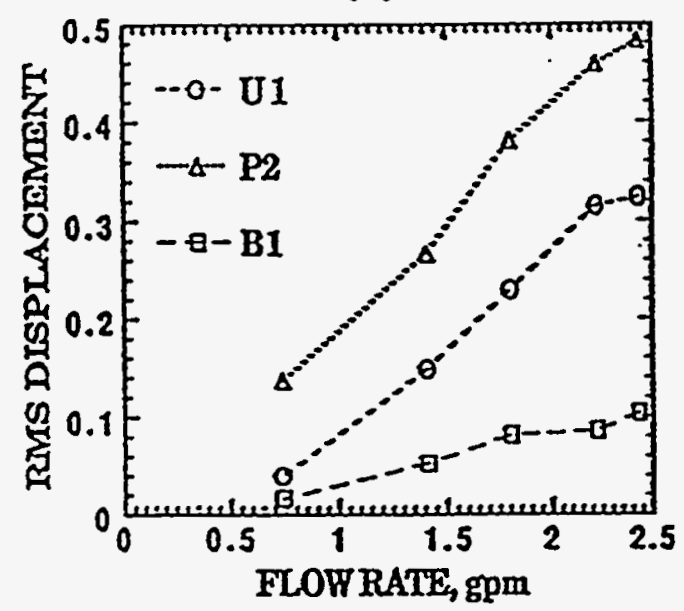

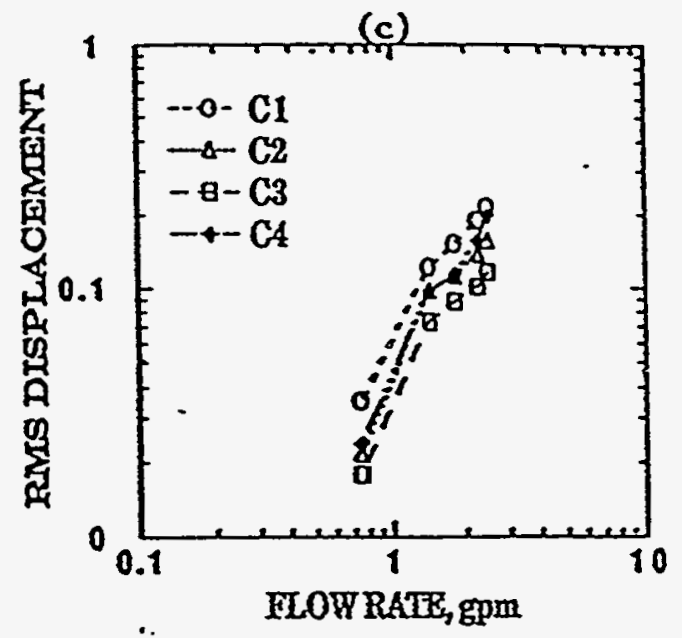

(d)

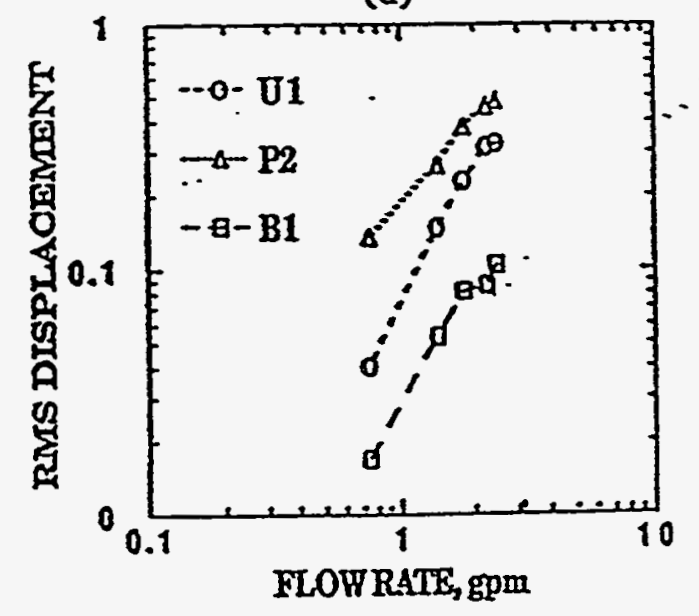

Fig. 21. RMS displacements in Test B.1, 20-200 Hz; all displacement values are in $\mu \mathrm{m}$ 
(a)

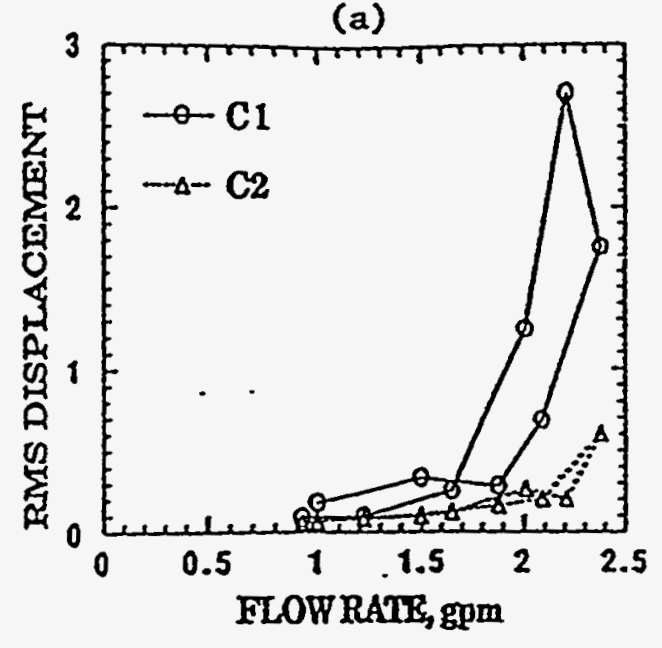

(b)

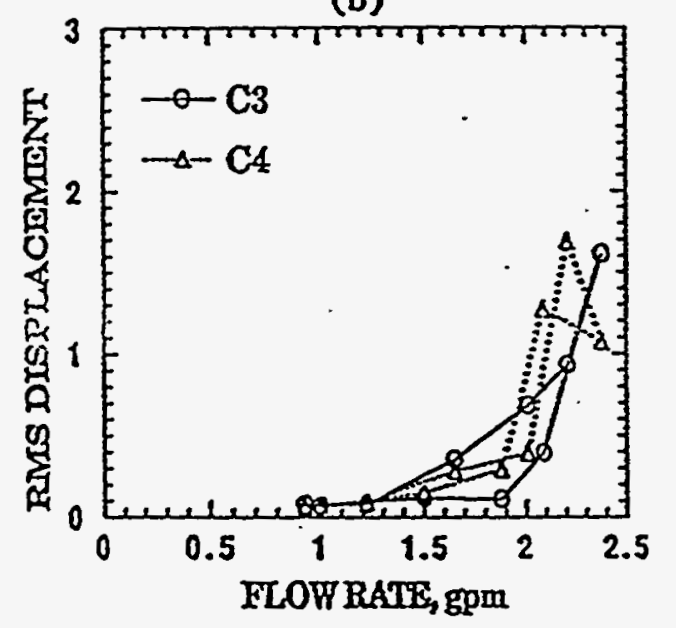

(c)

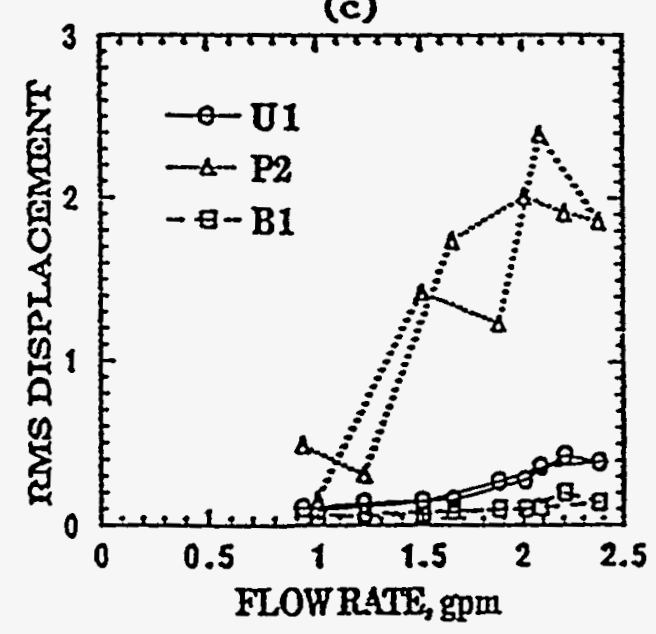

(d)

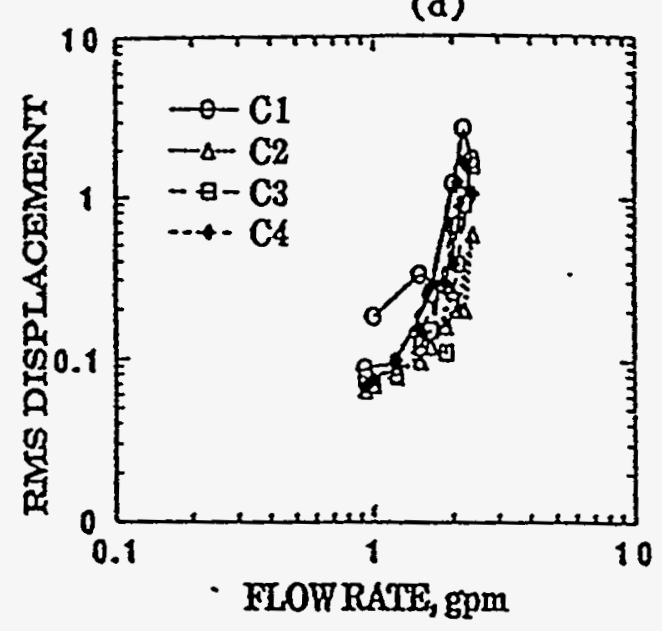

(e)

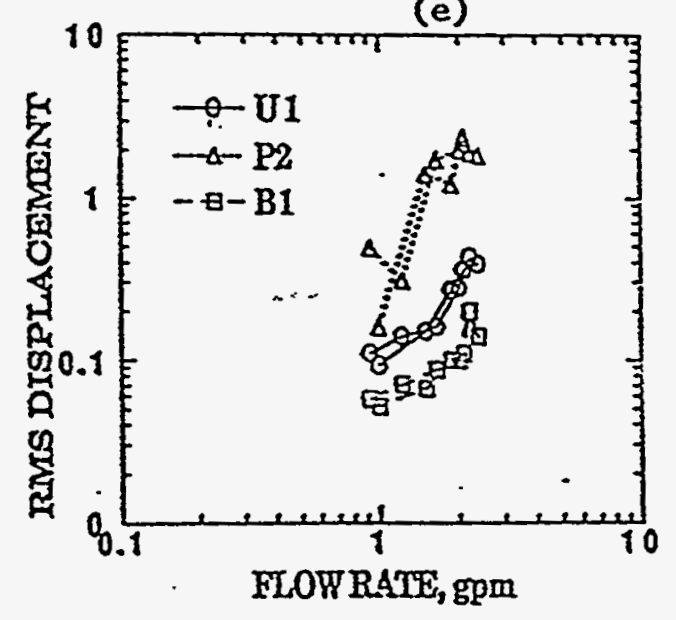

Fig. 22. RMS displacements in Test B.2; all displacement values are in $\mu \mathrm{m}$ 
(a)

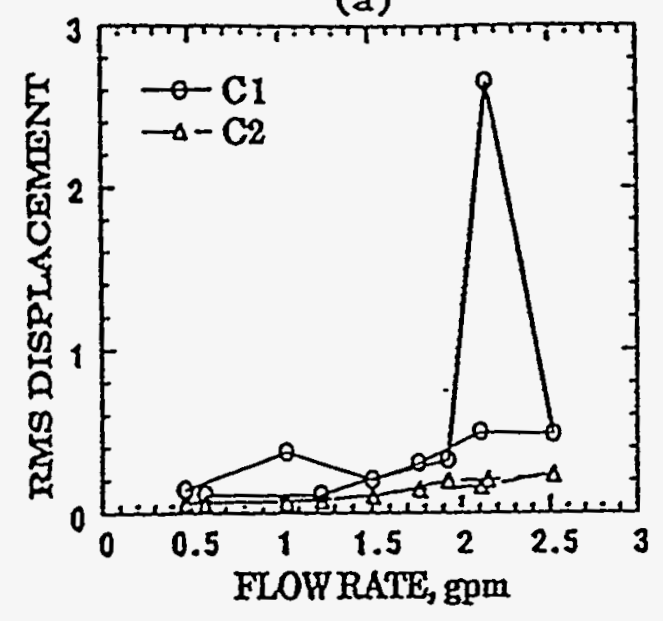

(b)

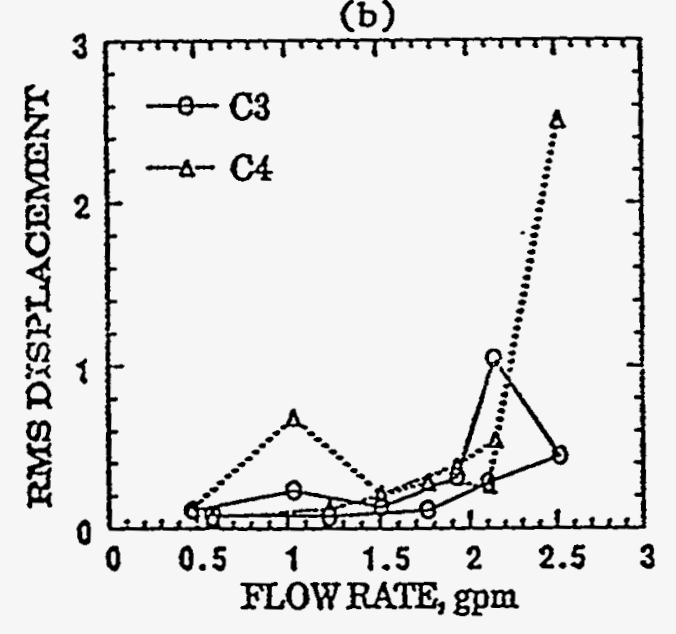

(c)

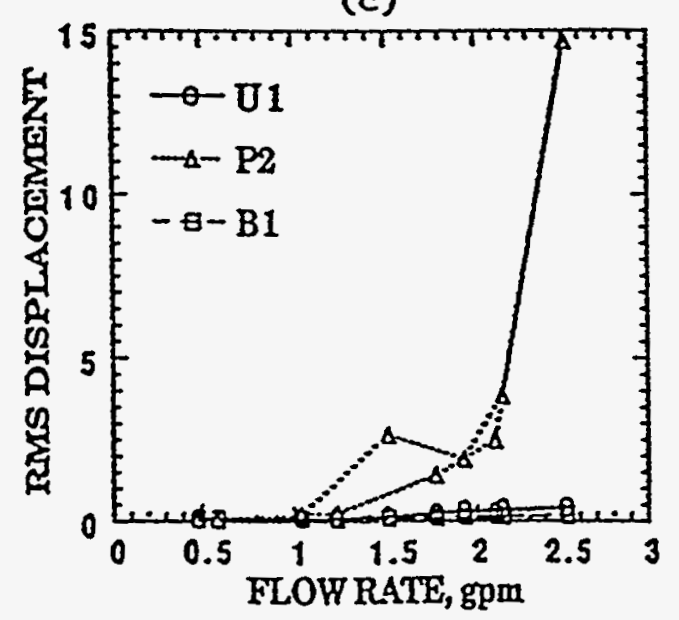

(d)

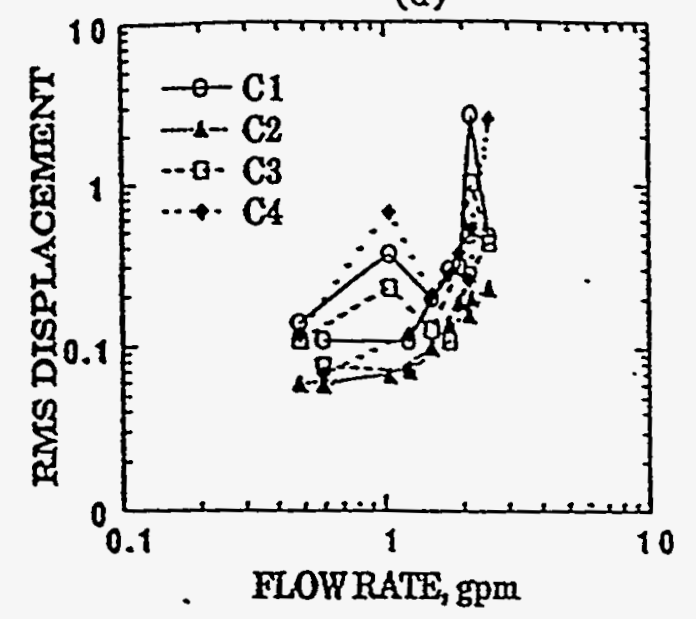

(e)

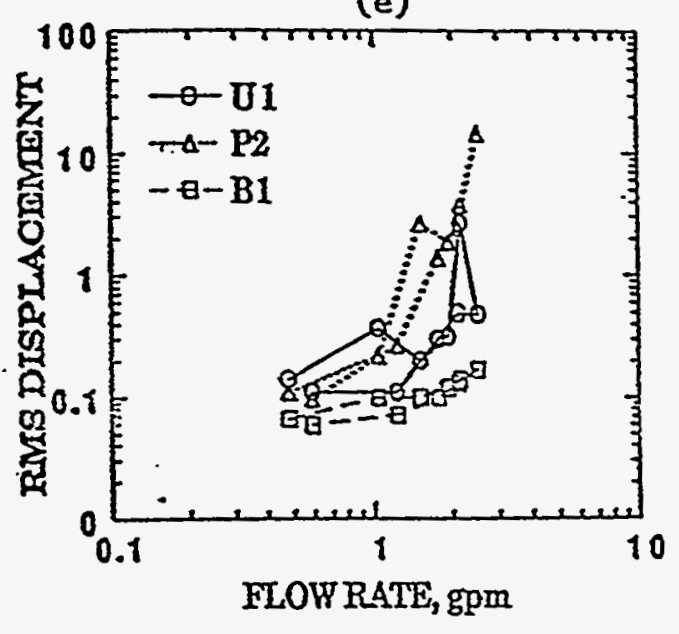

Fig. 23. RMS displacements in Test B.3; all displacement values are in $\mu \mathrm{m}$ 